\title{
Challenges associated with the sampling and analysis of organosulfur compounds in air using real-time PTR-ToF-MS and offline GC-FID
}

\author{
Véronique Perraud, Simone Meinardi, Donald R. Blake, and Barbara J. Finlayson-Pitts \\ Department of Chemistry, University of California, Irvine, CA 92697, USA \\ Correspondence to: Barbara J. Finlayson-Pitts (bjfinlay@uci.edu) and Donald R. Blake (drblake@uci.edu) \\ Received: 10 November 2015 - Published in Atmos. Meas. Tech. Discuss.: 15 December 2015 \\ Revised: 2 March 2016 - Accepted: 3 March 2016 - Published: 30 March 2016
}

\begin{abstract}
Organosulfur compounds (OSCs) are naturally emitted via various processes involving phytoplankton and algae in marine regions, from animal metabolism, and from biomass decomposition inland. These compounds are malodorant and reactive. Their oxidation to methanesulfonic and sulfuric acids leads to the formation and growth of atmospheric particles, which are known to influence clouds and climate, atmospheric chemical processes. In addition, particles in air have been linked to negative impacts on visibility and human health. Accurate measurements of the OSC precursors are thus essential to reduce uncertainties in their sources and contributions to particle formation in air. Two different approaches, proton-transfer reaction time-offlight mass spectrometry (PTR-ToF-MS) and canister sampling coupled to gas chromatography with flame ionization detector (GC-FID), are compared for both laboratory standards (dimethyl sulfide, DMS; dimethyl disulfide, DMDS; dimethyl trisulfide, DMTS; and methanethiol, MTO) and for a complex sample. Results show that both techniques produce accurate quantification of DMS. While PTR-ToF-MS provides real-time measurements of all four OSCs individually, significant fragmentation of DMDS and DMTS occurs, which can complicate their identification in complex mixtures. Canister sampling coupled with GC-FID provides excellent sensitivity for DMS, DMDS, and DMTS. However, MTO was observed to react on metal surfaces to produce DMDS and, in the presence of hydrogen sulfide, even DMTS. Avoiding metal in sampling systems seems to be necessary for measuring all but dimethyl sulfide in air.
\end{abstract}

\section{Introduction}

Organosulfur compounds (OSCs) such as methanethiol $\left(\mathrm{CH}_{3} \mathrm{SH}\right.$, MTO), dimethyl sulfide $\left(\mathrm{CH}_{3} \mathrm{SCH}_{3}, \mathrm{DMS}\right)$, dimethyl disulfide $\left(\mathrm{CH}_{3} \mathrm{SSCH}_{3}, \mathrm{DMDS}\right)$, and dimethyl trisulfide $\left(\mathrm{CH}_{3} \mathrm{SSSCH}_{3}\right.$, DMTS) have been measured in air (Nguyen et al., 1983; Andreae et al., 1985; Andreae, 1990; Andreae et al., 1993; Aneja, 1990; Bates et al., 1992; Watts, 2000; de Bruyn et al., 2002; Xie et al., 2002; Jardine et al., 2015). In marine environments, DMS is the major organosulfur compound emitted from phytoplankton decomposition and algae activities. Organosulfur compounds have also been reported from terrestrial biogenic sources including wetlands, soils, vegetation, and biomass burning (Goldan et al., 1987; Bates et al., 1992; Kesselmeier et al., 1993; Crutzen et al., 2000; Watts, 2000; Meinardi et al., 2003; Geng and Mu, 2006; Yi et al., 2008). In addition to these biogenic sources, several recent studies report organosulfur compound emissions from anthropogenic agricultural and composting activities and from animal waste (Burnett, 1969; Williams et al., 1999; Filipy et al., 2006; Mayrhofer et al., 2006; Kim et al., 2007; Shaw et al., 2007; Trabue et al., 2008; Feilberg et al., 2010; Papurello et al., 2012; Meinardi et al., 2013; Zhang et al., 2013). Atmospheric mixing ratios of OSCs range from a few ppt to hundreds of ppbs. Typically, ppt levels are reported in pristine marine environments and the free troposphere (Nguyen et al., 1983; Andreae, 1990; Crutzen et al., 2000; Watts, 2000; de Bruyn et al., 2002), with ppb concentrations in coastal ecosystems and wetlands (Watts, 2000). Concentrations of tens to hundred of ppt have been reported above vegetation, soil, and rice paddy fields (Crutzen et al., 2000; Geng and Mu, 2006; Yi et al., 2008; Jardine et al., 
2015) with some measurements above the canopy reaching a few ppb for DMS in some cases (Kesselmeier et al., 1993). Finally, much higher concentrations have been reported from local anthropogenic activities, such as livestock and animal and domestic waste, with levels reaching a few ppb to hundreds of ppb (Williams et al., 1999; Watts, 2000; Filipy et al., 2006; Kim et al., 2007; Feilberg et al., 2010; Papurello et al., 2012).

In the atmosphere, OSCs have short lifetimes with respect to $\mathrm{OH}$ radicals during the day and $\mathrm{NO}_{3}$ radicals at night, leading to the formation of sulfur dioxide $\left(\mathrm{SO}_{2}\right)$ (and ultimately sulfuric acid, $\mathrm{H}_{2} \mathrm{SO}_{4}$ ) and methanesulfonic acid (MSA, $\mathrm{CH}_{3} \mathrm{SO}_{3} \mathrm{H}$ ) (Hatakeyama and Akimoto, 1983; Grosjean, 1984; Barnes et al., 1988, 1994, 2006; Berresheim et al., 1990; Yin et al., 1990a, b; Tyndall and Ravishankara, 1991; Davison and Hewitt, 1994; Vandingenen et al., 1994; Capaldo and Pandis, 1997; Patroescu et al., 1999; FinlaysonPitts and Pitts Jr., 2000; Zhu et al., 2006; Berndt and Richters, 2012). For example, under a typical daytime $\mathrm{OH}$ concentration of $5 \times 10^{6} \mathrm{~cm}^{-3}$, the lifetime of DMS in air is about $8 \mathrm{~h}$, and for a typical nighttime $\mathrm{NO}_{3}$ of $5 \times 10^{8} \mathrm{~cm}^{-3}$ it is $\sim 30 \mathrm{~min}$. In the presence of water, amines/ammonia, $\mathrm{H}_{2} \mathrm{SO}_{4}$ and MSA are known to form new particles in air (Kulmala et al., 2004; Bzdek and Johnston, 2010; Smith et al., 2010; Dawson et al., 2012; Zhang et al., 2012). These newly formed particles can ultimately grow by uptake of organic vapors, amines/ammonia, and/or water to sizes capable of scattering sun light and impacting clouds, thus influencing the Earth's energy balance and climate (Finlayson-Pitts and Pitts Jr., 2000; Kulmala and Kerminen, 2008; Hallquist et al., 2009; Zhang et al., 2012; Kulmala et al., 2013). In addition, atmospheric particles have been previously linked to negatively affect health and visibility (Dockery et al., 1993; Hinds, 1999; Pope III et al., 2002; Pope III and Dockery, 2006).

Because of their key role in the formation of new particles in air, it is critical to account for all sources of OSCs. Several sample collection strategies have been applied over the years to the measurement of OSCs in air including the use of Tedlar ${ }^{\circledR}$ chambers (Hansen et al., 2011), metal canister or glass vessel-based methods (Kesselmeier et al., 1993; Williams et al., 1999; Simpson et al., 2001; Meinardi et al., 2003; Blunden et al., 2005; Trabue et al., 2008; Beyersdorf et al., 2010; Guo et al., 2010; Khan et al., 2012; Meinardi et al., 2013; Zhang et al., 2013), solid sorbents (Filipy et al., 2006) or sorptive metal (Andreae et al., 1985), solid-phase microextraction (Xie et al., 2002; Lestremau et al., 2004), and cryotraps (Hofmann et al., 1992; de Bruyn et al., 2002). Subsequent analysis of the collected sample is typically performed by gas chromatography (GC). However, quantifying these species is quite challenging due to their oxidation and loss on surfaces (Kuster and Goldan, 1987; Devai and Delaune, 1994; Katoh et al., 1995; Wardencki, 1998; Sulyok et al., 2002; Bashkova et al., 2003; Lestremau et al., 2004; Kim et al., 2006; Andersen et al., 2012). More recently, proton-transfer reaction mass spectrometry (PTR-MS) has been applied to the measurement of these species from various sources (Crutzen et al., 2000; Hayward et al., 2002; Aprea et al., 2007; Shaw et al., 2007; Feilberg et al., 2010; Kai et al., 2010; Hansen et al., 2012a, 2013; Papurello et al., 2012; Koga et al., 2014) including breath (Taucher et al., 1996; Herbig et al., 2009) and food (Aprea et al., 2007). This technique provides a fast response, high sensitivity, and generally relatively low fragmentation. It has been increasingly applied to the measurement of volatile organic compounds; however, it is sensitive only to molecules that have a proton affinity higher than that of water, and several classes of compounds are subject to fragmentation (Buhr et al., 2002; Tani et al., 2003; Maleknia et al., 2007; Kim et al., 2009; Brown et al., 2010; Gueneron et al., 2015), which complicates attributions of peaks in complex mixtures. In addition, despite the fact that sample collection is not required, uptake or displacement on sampling lines can occur for some compounds (Christian et al., 2004; Mikoviny et al., 2010; Freshour et al., 2014).

In this paper, we report a comparison between two techniques for the measurements of OSCs in air, including direct real-time measurements by proton-transfer reaction time-offlight mass spectrometry (PTR-ToF-MS) and offline stainless steel canister sampling coupled to gas chromatography with flame ionization detector (GC-FID). Advantages and challenges associated with these two techniques are discussed with respect to sampling complex mixtures.

\section{Materials and methods}

\section{$2.1 \quad$ PTR-ToF-MS}

Measurements of OSCs in air were performed using a highresolution PTR-ToF-MS (model 8000, Ionicon Analytik). This instrument has been described previously (Jordan et al., 2009; Graus et al., 2010) and only the key features related to this particular study are presented here. The air sample was introduced via heated $1 / 16^{\prime \prime} \mathrm{PEEK}^{\circledR}$ tubing maintained at $70^{\circ} \mathrm{C}(343 \mathrm{~K})$ at a constant flow of $150 \mathrm{~cm}^{3} \mathrm{~min}^{-1}$. The instrument was operated under the standard ion drift tube conditions with a total voltage of $600 \mathrm{~V}\left(U_{\text {drift }}\right)$ and pressure between 2.10 and $2.15 \mathrm{mbar}\left(p_{\text {drift }}\right)$. Under these conditions, the ratio of the electric field $(E)$ to the number density $(N)$ of the drift tube buffer gas molecules $(E / N)$ was kept at values of 130-133 Townsends (Td) $\left(1 \mathrm{Td}=10^{-17} \mathrm{~cm}^{2} \mathrm{~V}\right.$ molecule $\left.{ }^{-1}\right)$ throughout all measurements, leading to the predominance of the cluster $\mathrm{H}_{3} \mathrm{O}^{+}$in the ion drift over the higher mass water clusters (de Gouw and Carsten, 2007). Collisions of the $\mathrm{H}_{3} \mathrm{O}^{+}$ions with a volatile organic compound generally results in a proton transfer reaction if the compound has a proton affinity (PA) higher than that of water $\left(\mathrm{PA}\left(\mathrm{H}_{2} \mathrm{O}\right)=691 \mathrm{~kJ} \mathrm{~mol}^{-1}\right)$. The chemical ionization process is generally considered "soft" and in most cases generates a parent ion at $[\mathrm{M}+\mathrm{H}]^{+}$. However, many re- 
active compounds fragment, and all fragments must be taken into account to estimate the mixing ratios of the targeted species if they are derived from PTR-ToF-MS parameters rather than calibration with standards (Kim et al., 2009).

In this work, the mixing ratios of each OSC, $C_{\mathrm{ppb}}$, were quantified based on Eq. (1):

$C_{\mathrm{ppb}}=\frac{1}{S} \times \frac{\sum\left(I_{\mathrm{mz}}-I_{\mathrm{mz} \_ \text {background }}\right)}{\left(\frac{I_{\mathrm{H}_{3} \mathrm{O}^{+}}}{10^{6}}\right)}$,

where $S$ is a calibration factor (or sensitivity) for the target OSCs expressed in normalized counts per second per ppbv $\left(n c p s p p b^{-1}\right)$, determined experimentally using pure standards; $I_{\mathrm{mz}}$ and $I_{\mathrm{mz}}$ background are the raw and background ion signal in counts per second (cps), respectively, for one given OSC mass fragment; and $\left(\mathrm{I}_{\mathrm{H}_{3} \mathrm{O}^{+}}\right)$is the ion signal in cps for the hydronium ion. The hydronium ion counts were in the range $(0.7-2.90) \times 10^{6} \mathrm{cps}$ over the entire period of the study. In practice, $I_{\mathrm{H}_{3} \mathrm{O}^{+}}$is normalized to $10^{6} \mathrm{cps}$ to yield normalized counts per seconds (ncps). For each OSC, quantification was evaluated using the sum of the major fragments, although in principle one peak would be sufficient when calibrations are carried out independently using authentic compounds (see Sect. 3.1). It is important to note that the calibration factor $S$ depends strongly on the operating conditions, maintenance, and tuning of the instrument and as a result may differ between studies. Calibrations were performed regularly during the entire period of the study to ensure proper quantification. Multiple analyses of the same OSC standard concentration were used to evaluate the dayto-day instrument variation, from which an uncertainty of $\sim 30 \%(2 \sigma)$ was derived for any given reported mixing ratio.

An alternative method for determining mixing ratios of volatile organic compounds directly from the PTR-ToF-MS source parameters $\left(U_{\text {drift }}, p_{\text {drift }}, T_{\text {drift }}\right.$, length of the reaction chamber, etc.), measured ion transmission efficiencies $\left(T_{r}\right)$, published values of the kinetic rate constant $(k)$ between $\mathrm{H}_{3} \mathrm{O}^{+}$and the targeted OSC, and the reduced ion mobility of $\mathrm{H}_{3} \mathrm{O}^{+}$ions $\mu_{o}\left(=2.8 \mathrm{~cm}^{2} \mathrm{~V}^{-1} \mathrm{~s}^{-1}\right)$ was described previously (de Gouw and Carsten, 2007) (see the Supplement). However, this method requires determining the transmission efficiencies accurately as well as having evaluated and recommended rate constants for OSCs with $\mathrm{H}_{3} \mathrm{O}^{+}$ions, for which data are scarce (Passarella et al., 1987; Arnold et al., 1998; Lindinger et al., 1998; Španěl and Smith, 1998; Williams et al., 1998; Wang et al., 2004; Zhao and Zhang, 2004; Blake et al., 2009; Cappellin et al., 2010). As a result, this method typically yields larger uncertainties on the estimated mixing ratios.

In this work, mass spectra and temporal ion signal profiles were extracted using the PTR-MS TOF Viewer software (Ionicon Analytik version 1.4.0) and a custom modified Gaussian function fit for each peak. The PTR-ToFMS is equipped with a time-of-flight mass filter with a manufacturer-stated resolution of $\sim 5000$, which allows for accurate mass determination. The resolution of the instrument for the full mass range of interest was verified using a mixture of 14 aromatic compounds in nitrogen (mixing ratios of $\sim 100 \mathrm{ppb}$; TO-14 mix, Linde) and gave resolutions higher than 4000 for mass-to-charge ratios ranging from $\mathrm{m} / z, 79$ to 181 , which is sufficient to resolve the peaks of interest in this study. The lock masses used for the accurate mass determination were the isotopic peaks of the protonated water ion at $m / z 21.0226\left(\left[\mathrm{H}_{3}^{18} \mathrm{O}\right]^{+}\right)$and the protonated acetone $[\mathrm{M}+\mathrm{H}]^{+}$ion at $m / z 59.0497$, which was always present in room air sampled at the beginning of each run. For the source samples, the protonated ion for acetone at $\mathrm{m} / z 59$ could not be used because it was also found in sufficiently high concentration to saturate the detector, so the masses $\mathrm{m} / z 21.0226$ $\left(\left[\mathrm{H}_{3}^{18} \mathrm{O}\right]^{+}\right.$) and $m / z 123.946$ (a common contaminant peak corresponding to $\mathrm{SiO}_{6}^{+}$ion) were used instead.

\subsection{Canister sampling coupled with GC-FID analysis}

Samples were collected into evacuated $2 \mathrm{~L}$ electropolished stainless steel canisters. Prior to sampling, the canisters were cleaned and conditioned according to a procedure described previously (Blake et al., 1994). It has been shown that in order to increase the stability of certain compounds in the canister as well as provide reproducible split ratios at the injection, small amounts of water must be present in the canister prior to analysis (Colman et al., 2001). Ambient samples always contain some water; however, laboratory generated standards do not. Thus, for an appropriate analysis of the standards, 18-20 Torr of water vapor was added prior to sampling (hereafter referred to as water-doped canisters), but no water was added to the ambient air canister samples.

At the beginning of an ambient air sample collection, the inlet valve of the canister was fully opened so that the canister reached its final pressure of $\sim 15 \mathrm{psig}$ ( $1 \mathrm{~atm}$ ) in less than $1 \mathrm{~min}$. The canisters were analyzed the same day as the collection. For analysis of each canister, $1350 \mathrm{~cm}^{3}$ of air sample was concentrated by pumping it through a stainless steel loop $(10 \mathrm{~mL})$ filled with glass beads immersed in liquid nitrogen. This procedure assures trapping of most of the organic compounds of interest while more volatile species such as $\mathrm{CH}_{4}, \mathrm{~N}_{2}, \mathrm{O}_{2}$, Ar, etc. are pumped away. The concentrated sample was then vaporized by heating the loop with hot water $\left(\sim 80^{\circ} \mathrm{C}\right)$ and injected into a parallel three-GC system (Hewlett-Packard) using $\mathrm{He}$ as the carrier gas. Details of the complete analytical system can be found elsewhere (Colman et al., 2001). The OSCs of interest were identified by comparison with standards and quantified using a flame ionization detector.

\subsection{Gas-phase OSC standards}

A gas mixture containing $1.02 \pm 0.05 \mathrm{ppm}$ (uncertainty taken as $1 \sigma$ ) of DMS and $0.948 \pm 0.047 \mathrm{ppm}$ (uncertainty taken as $1 \sigma$ ) of DMDS in nitrogen was obtained from Scott- 
Marrin and used for calibration (uncertainties provided by the supplier). In addition, generation of gas-phase OSCs was achieved by injecting a solution of the pure standards in cyclohexane (Fluka, Spectranalyzed grade), using a syringe pump (Pump systems Inc., model NE-1000), into a stream of dry synthetic air (ultra zero air, $99.999 \%$, Praxair) following a method similar to that described by Jardine and coworkers (Jardine et al., 2010) (see Fig. S1 in the Supplement for details), hereafter referred to as the dynamic injection system. The standards included DMS ( $\geq 99 \%$, Sigma-Aldrich), DMDS ( $\geq 99 \%$, Sigma-Aldrich), and DMTS ( $\geq 98 \%$, SAFC). The mixing ratios after dilution were estimated using error propagation analysis (Harris, 1991), with an estimated accuracy of $\pm 10 \%(2 \sigma)$ for the DMS/DMDS gas cylinder, and $\pm 20 \%(2 \sigma)$ for the mixtures from the dynamic injection system.

A certified gas mixture containing 4.03 ppm of MTO was obtained from Airgas. In addition, a pure gas-phase MTO standard from Matheson (purity 99\%) was used to prepare our own gas mixture in the laboratory using a glass manifold. Ultra zero grade air was supplied from Praxair for dilution. The uncertainty in the mixing ratio of MTO in the primary mixture prepared this way was estimated to be $\pm 1 \%(2 \sigma)$. Further dilution of the primary mixture prepared in a $6 \mathrm{~L}$ glass bulb was used for calibration as described in Sect. 3.2.

Lastly, for a separate series of experiments, generation of gas-phase DMTS, MTO, and hydrogen sulfide $\left(\mathrm{H}_{2} \mathrm{~S}\right)$ standards was performed using commercially available permeation devices (VICI), which were each enclosed in an individual U-shaped glass tube and maintained at $50{ }^{\circ} \mathrm{C}$ using a thermostated water bath (LAUDA, model M20). While an individual sealed tube (or tubular device) was used for MTO and DMTS, the $\mathrm{H}_{2} \mathrm{~S}$ liquid standard was enclosed in a stainless steel wafer device (wafer device type 30F3, VICI), which only permeates through a small opening in a tetrafluoroethylene membrane located at the bottom of the device to allow a slow permeation rate to be obtained. A flow of $200 \mathrm{~cm}^{3} \mathrm{~min}^{-1}$ dry, filtered air purified by passing through a Fourier transform infrared purge gas generator (Parker Balston Model 75-62), carbon/alumina media (Perma Pure, LLC), and an inline $0.1 \mu \mathrm{m}$ filter (DIF-N70; Headline Filters) served as the carrier gas and diluent through the $\mathrm{U}$ shaped glass tube. Permeation rates for MTO and $\mathrm{H}_{2} \mathrm{~S}$ were determined gravimetrically giving values of $337 \pm 106$ and $133 \pm 14 \mathrm{ng} \mathrm{min}^{-1}$, respectively. The uncertainties represent those from repeated weight measurements and are higher for MTO than stated by the manufacturer (30 vs. $15 \%)$ and lower for $\mathrm{H}_{2} \mathrm{~S}$ ( 10 vs. $25 \%$ ). The accuracy of the mixing ratios after dilution were estimated to be the same as that estimated for the primary gas-phase mixing ratio, as this is the higher uncertainty in the system. It was not possible to determine accurately the absolute permeation rate for DMTS due to large variations in the weight of the tube and the presence of some DMDS in the outflow; however, even if the gas-phase generation system could not be used for absolute calibration of DMTS, as described in Sect. 3.3, it was useful for the stability study in which only relative mixing ratios were needed.

\subsection{Sampling from a complex high-emission source}

To compare the performance of both measurement methods on an urban source, the headspace above street waste bins from a residential area with many pets was sampled with both the PTR-ToF-MS and the canister/GC-FID method. Since it is known that livestock in agricultural areas is a significant source of OSCs (Burnett, 1969; Williams et al., 1999; Filipy et al., 2006; Kim et al., 2007; Shaw et al., 2007; Trabue et al., 2008; Feilberg et al., 2010; Papurello et al., 2012; Meinardi et al., 2013; Zhang et al., 2013), the same might be expected for the bins. Two bins were sampled repeatedly: a $135 \mathrm{~L}$ bin and a $21 \mathrm{~L}$ bin, the contents of which had varied weights (1$8 \mathrm{lb}$ ). Before each sampling period, the bin was opened to ambient air to clear out the headspace above the sample. The PTR-ToF-MS inlet was then attached to the lid of the bin, and the sampling started when the lid was repositioned on the bin. This approach allowed for the measurement of emission rates of the sulfur compounds from the bin. After each 20 min sampling period with the PTR-ToF-MS, one canister was attached to the sampling line of the bin and a sample was taken for comparison. Blank measurements from the bins themselves and plastic bin liners were also performed and show no detectable OSC compounds.

\section{Results and Discussion}

\subsection{Fragmentation pattern of the OSCs in the PTR-ToF-MS}

Signal response and fragmentation patterns in the PTRToF-MS were investigated from the analysis of the pure OSC standards (Fig. 1). DMS, DMDS, and MTO have known proton affinities (Lide, 1994) of 830.9, 815.3, and $773.4 \mathrm{~kJ} \mathrm{~mol}^{-1}$, respectively, well above the proton affinity of water $\left(691 \mathrm{~kJ} \mathrm{~mol}^{-1}\right)$. As a result, these compounds are expected to be efficiently ionized in the PTR-ToF-MS and no relative humidity dependence of the signal is expected for these compounds. There are no reported values for the proton affinity for DMTS, but this compound is expected to behave similarly to DMS and DMDS.

As seen in Fig. 1a and b, MTO and DMS give one major peak corresponding to their respective protonated $[\mathrm{M}+\mathrm{H}]^{+}$ ions at nominal masses $m / z 49$ and 63, respectively. Accurate mass determination shows very good agreement with the expected elemental composition for the protonated ion within $-0.6 \mathrm{mDa}$ of the expected masses (Table 1 and Fig. S2). In addition, the isotopic distribution for both parent ions agrees well with the presence of one single sulfur atom in the molecule with an ${ }^{34} \mathrm{~S} /{ }^{32} \mathrm{~S}$ isotopic ratio of $\sim 4 \%$ (Berglund and Wieser, 2011). 
(a) Methanethiol (MTO)

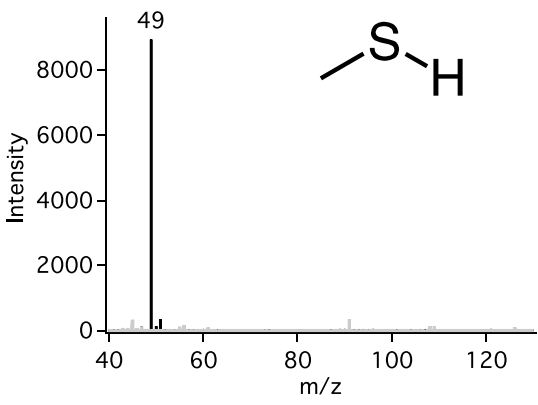

(c) Dimethyl disulfide (DMDS)

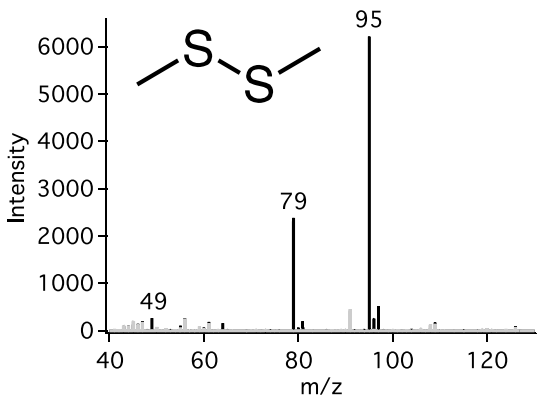

(b) Dimethyl sulfide (DMS)

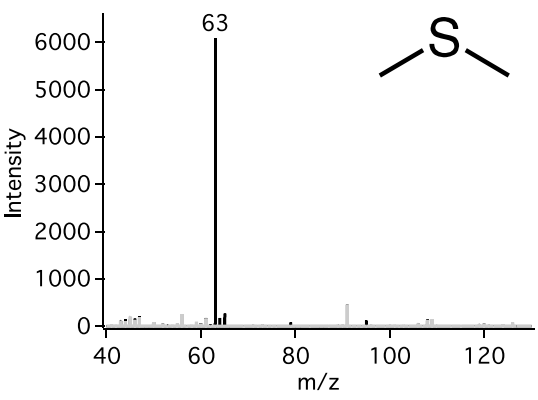

(d) Dimethyl trisulfide (DMTS)

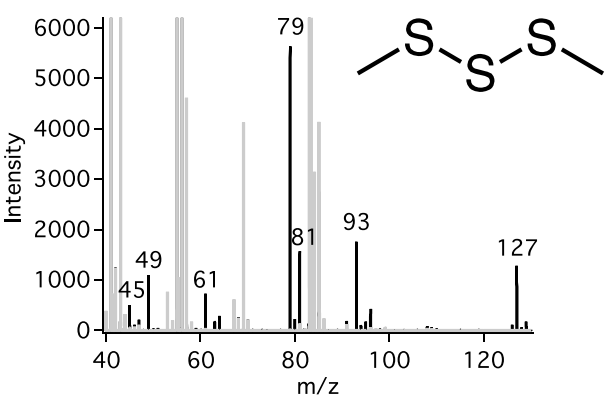

Figure 1. Individual PTR-ToF-MS mass spectra for each organosulfur compound: (a) methanethiol (MTO) from the laboratory-generated gas-phase standard, (b) dimethyl sulfide (DMS) and (c) dimethyl disulfide (DMDS) from injection of the individual pure liquid standards into air in a $100 \mathrm{~L}$ Teflon chamber, and (d) dimethyl trisulfide (DMTS) from the dynamic injection system. In spectra (b) and (c), the gray peaks correspond to ion fragments resulting from the ionization of background species in the Teflon chamber; in (d), the gray peaks correspond to ion fragments resulting from the ionization of cyclohexane, which is used here as the solvent.

Table 1. Accurate mass and elemental composition of the major fragments observed for the analysis of standard organosulfur compounds by PTR-ToF-MS

\begin{tabular}{llrcrr}
\hline & $\begin{array}{l}\text { Accurate } \\
\text { mass (Da) }\end{array}$ & $\begin{array}{r}\text { Intensity } \\
(\%)\end{array}$ & $\begin{array}{c}\text { Elemental } \\
\text { composition }\end{array}$ & $\begin{array}{r}\text { Exact } \\
\text { mass (Da) }\end{array}$ & $\begin{array}{c}\text { Absolute mass } \\
\text { difference }(\mathrm{mDa})^{\mathrm{a}}\end{array}$ \\
\hline $\begin{array}{l}\text { Methanethiol } \\
\text { (MTO) }\end{array}$ & 49.0106 & 100 & {$\left[\mathrm{CH}_{3} \mathrm{SH}+\mathrm{H}\right]^{+}$} & 49.0112 & -0.6 \\
\hline $\begin{array}{l}\text { Dimethyl sulfide } \\
\text { (DMS) }\end{array}$ & 63.0262 & 100 & {$\left[\mathrm{CH}_{3} \mathrm{SCH}_{3}+\mathrm{H}\right]^{+}$} & 63.0268 & -0.6 \\
\hline Dimethyl disulfide & $94.9984^{\mathrm{b}}$ & 100 & $\left.\mathrm{CH}_{3} \mathrm{SSCH}_{3}+\mathrm{H}\right]^{+}$ & 94.9989 & -0.5 \\
(DMDS) & $78.9667^{\mathrm{b}}$ & 38 & $\mathrm{CH}_{3} \mathrm{SS}^{+}$ & 78.9676 & -0.9 \\
& 49.0102 & 4 & $\mathrm{CH}_{3} \mathrm{SH}_{2}^{+}$ & 49.0112 & -1.0 \\
\hline Dimethyl trisulfide & $126.9718^{\mathrm{c}}$ & 23 & $\left.\mathrm{CH}_{3} \mathrm{SSSCH}_{3}+\mathrm{H}\right]^{+}$ & 126.9710 & +0.8 \\
(DMTS) & $92.9836^{\mathrm{c}}$ & 31 & $\mathrm{CH}_{3} \mathrm{SSCH}_{2}^{+}$ & 92.9833 & +0.3 \\
& $80.9806^{\mathrm{c}}$ & 28 & $\mathrm{CH}_{3} \mathrm{SSH}_{2}^{+}$ & 80.9833 & -2.7 \\
& $78.9680^{\mathrm{c}}$ & 100 & $\mathrm{CH}_{3} \mathrm{SS}^{+}$ & 78.9676 & +0.4 \\
& 61.0122 & 13 & $\mathrm{CH}_{3} \mathrm{SCH}_{2}^{+}$ & 61.0112 & +1.0 \\
& 49.0108 & 19 & $\mathrm{CH}_{3} \mathrm{SH}_{2}^{+}$ & 49.0112 & -0.4 \\
& 44.9797 & 9 & $\mathrm{CHS}^{+}$ & 44.9799 & -0.2 \\
\hline
\end{tabular}

a All reported data are within the $3 \mathrm{mDa}$ acceptable mass difference defined by the

Journal of Organic Chemistry (Greaves and Roboz, 2013).

${ }^{b}$ Fragments used for quantification of DMDS

${ }^{c}$ Fragments used for quantification of DMTS. 
The mass spectrum of the DMDS standard (Fig. 1c) shows a base peak at nominal mass $m / z 95$ corresponding to the $[\mathrm{M}+\mathrm{H}]^{+}$ion and a fragment at $m / z$ 79. Accurate mass determination (Table 1 and Fig. S2) confirmed the identity of the parent ion at $m / z 94.9984(-0.5 \mathrm{mDa}$ away from $\left[\mathrm{CH}_{3} \mathrm{SSCH}_{3}+\mathrm{H}\right]^{+}$exact mass), and the ion at $m / z 78.9667$ was attributed to the $\mathrm{CH}_{3} \mathrm{SS}^{+}$ion fragment $(-0.9 \mathrm{mDa}$ mass difference). Under our experimental conditions, the peak intensity at $m / z, 79$ was $\sim 38 \%$ of the base peak $(\mathrm{m} / z$ 95). In the PTR-ToF-MS, the fragmentation of one species is generally governed by the electric field strength $(E / N)$ applied to the drift tube (Tani et al., 2003; Brown et al., 2010; Gueneron et al., 2015). Our experiments were carried out at an $E / N$ of $130-133$ Td. Schuhfried et al. (2013) studied the fragmentation of DMDS at different $E / N$ values using density functional calculations and reported a value for $m / z 79$ contribution between $20.7 \%$ at $E / N=127 \mathrm{Td}$ and $66.3 \%$ at $E / N=140 \mathrm{Td}$. Our work is in good agreement with these calculations (Fig. S3). In addition, a very small fragment at $m / z 49$ from the DMDS standard was observed with an intensity of $\sim 4 \%$ of the base peak $(\mathrm{m} / z$ 95), which is in good agreement with the value of $5 \%$ predicted by Schuhfried et al. (2013).

Compared to the smaller OSCs, DMTS shows much more fragmentation in PTR-ToF-MS. Figure 1d shows the mass spectrum obtained when sampling the DMTS standard from the dynamic injection system. Peaks corresponding to the protonated ion $[\mathrm{M}+\mathrm{H}]^{+}$and $\mathrm{CH}_{3} \mathrm{SS}^{+}$ions were observed at $m / z 126.9718(+0.8 \mathrm{mDa}$ mass difference from $\left[\mathrm{CH}_{3} \mathrm{SSSCH}_{3}+\mathrm{H}\right]^{+}$exact mass) and $\mathrm{m} / z 78.9680$ (+0.4 $\mathrm{mDa}$ mass difference from $\mathrm{CH}_{3} \mathrm{SS}^{+}$exact mass), respectively. Five additional peaks, previously reported as fragments in the DMTS mass spectrum (Mockel and Weiss, 1980), were observed at nominal masses $m / z$ 93, 81, 61, 49 , and 45 and were assigned to $\mathrm{CH}_{3} \mathrm{SSCH}_{2}^{+}, \mathrm{CH}_{3} \mathrm{SSH}_{2}^{+}$, $\mathrm{CH}_{3} \mathrm{SCH}_{2}^{+}, \mathrm{CH}_{3} \mathrm{SH}_{2}^{+}$, and $\mathrm{CHS}^{+}$, respectively. These assignments are supported by the excellent agreement with the exact masses (see Fig. S2 and Table 1). It is important to note that the peak at $m / z 80.9806$ corresponds here to a fragment and is not due to the isotopic distribution of the major fragment at $m / z 78.9680$ (see Fig. S2). The intensity observed at $m / z 80.9806$ is $28 \%$ of that of the peak at nominal mass $m / z$ 79. This is much larger than the isotopic distribution expected for sulfur containing compounds, which would be $8.9 \%$ for a $\left[\mathrm{CH}_{3}{ }^{3}{ }^{32} \mathrm{~S}_{-}{ }^{34} \mathrm{~S}\right]^{+}$fragment (Berglund and Wieser, 2011). Finally, although a peak at nominal mass $m / z 96$ was also observed in the mass spectra of DMTS, accurate mass determination precluded the assignment to an $\mathrm{S}_{3}^{+}$fragment (Fig. S4) and the identity of this minor fragment remains unknown. This fragment was previously reported by Mockel and Weiss (Mockel and Weiss, 1980) from DMTS chemical ionization mass spectrometry analysis; however, the study was done using a quadrupole mass spectrometer which cannot provide exact mass information. In the present study, the relative intensities of the fragments observed, taking the base peak at $m / z, 79$ to be 100 , are $9: 19: 13: 100: 28: 31: 8: 23$ for $m / z 45,49,61,79,81,93,96$, and 127 , respectively.

\subsection{Quantification of OSCs by PTR-ToF-MS}

Calibration of the PTR-ToF-MS for DMS, DMDS, and DMTS was performed using successive dilutions of the $1 \mathrm{ppm}$ certified gas cylinder for DMS/DMDS and the outflow of the dynamic injection system for DMTS. The dynamic injection system was also used with DMS and DMDS standards to validate the technique. Very good agreement between the gas cylinder and dynamic injection system was observed for DMS/DMDS (Fig. S5), supporting its application to DMTS calibration. Measurements showed a linear dynamic range from 0 to $\geq 250 \mathrm{ppb}$ for all three sulfides (Fig. S5). Analytical limits of detection were estimated as $3 \sigma$ of the baseline noise, where peak-to-peak baseline variation was taken as $5 \sigma$ (Skoog and Holler, 2007). Limits of detection (LODs) for DMS and DMDS were both $49 \pm 15 \mathrm{ppt}$, while the LOD for DMTS was $81 \pm 24$ ppt.

Calibration for MTO was more difficult to achieve due to its loss and reactivity on surfaces. For example, losses on metal surfaces were observed when placing a $\sim 20 \mathrm{~cm}$ stainless steel or copper tubing in the sampling line between the certified 4.3 ppm MTO gas cylinder and the PTR-ToF-MS inlet. Figure S6 shows a drastic loss of MTO in both cases as soon as the metal tube is inserted. In addition, PTR-ToF-MS analysis from the certified gas cylinder revealed that DMDS was formed inside the regulator, which precluded the use of this standard for calibration (Fig. S6). As an alternative, we chose to perform the PTR-ToF-MS calibration using our own laboratory generated gas-phase mixture of MTO in clean dry synthetic air from a gas cylinder of pure MTO. Once extracted from the cylinder, the gas was never in contact with any metal tubing or connectors. Known amounts of the pure standard were transferred into a previously evacuated $5 \mathrm{~L}$ glass bulb that was pumped on overnight. Successive dilutions in clean dry synthetic air were then made using a glass manifold to reach a final mixing ratio of $4.08 \pm 0.04 \mathrm{ppm}$ MTO. This mixture was stored in a separate previously evacuated $6 \mathrm{~L}$ glass bulb overnight to make sure the mixture was well mixed in the bulb prior to its use. During preparation of the mixture, there was no evidence for MTO loss on the glass surfaces, consistent with the observation of Devai and Delaune (1994) who reported a $90 \%$ recovery after $24 \mathrm{~h}$ for MTO samples prepared in dry air in a $125 \mathrm{~mL}$ glass bulb. Calibration mixtures were prepared by diluting a flow of $50 \mathrm{~cm}^{3} \mathrm{~min}^{-1}$ of the bulb contents with a flow of 1 to $7.5 \mathrm{~L} \mathrm{~min}^{-1}$ of dry synthetic air. No evidence of any other OSC was observable in the PTR-ToF-MS spectra, apart from MTO. A linear dynamic range was observed from 0 to $200 \mathrm{ppb}$ (Fig. S5) and an LOD of $65 \pm 20 \mathrm{ppt}$ was determined. 

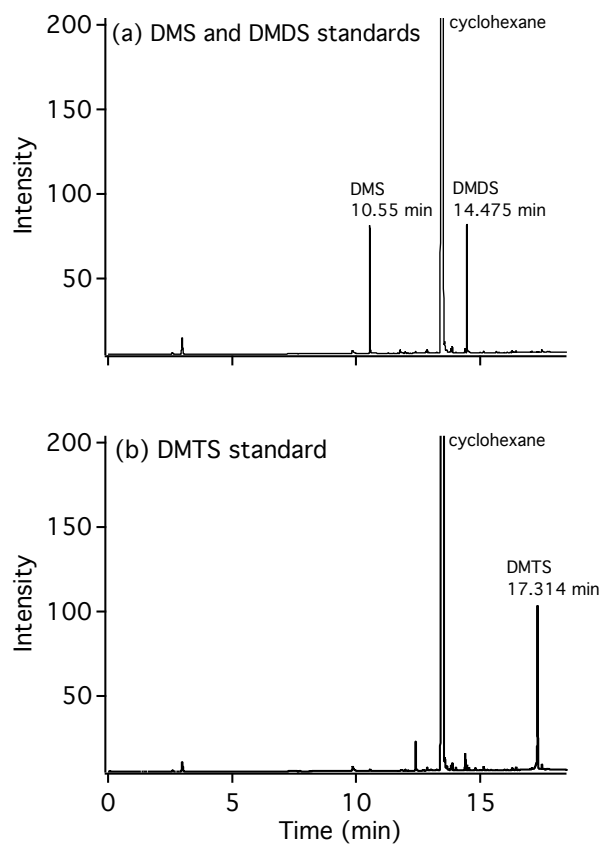

Figure 2. GC-FID chromatogram for (a) DMS $(\sim 21 \mathrm{ppb})$ and DMDS $(\sim 20 \mathrm{ppb})$ and (b) DMTS $(\sim 22 \mathrm{ppb})$ standards from the dynamic injection system. The cyclohexane peak is due to the solvent used in the injection system. Analysis followed immediately after canister samples were prepared.

\subsection{Analysis of OSC standards using the canisters and GC-FID}

Quantification of DMS and DMDS (but not DMTS) using electropolished stainless steel canisters has been previously reported (Colman et al., 2001; Simpson et al., 2001; Meinardi et al., 2003, 2013; Beyersdorf et al., 2010; Guo et al., 2010). In this study, identification of the retention times for the three sulfides was performed by running standards (Fig. 2). The responses obtained from the FID were converted from area units into mixing ratios based on a per-carbon response factor (PCRF) as described previously (Simpson et al., 2001). Because the three sulfides contain two methyl carbons, and are thus likely to have the same FID response, we assigned a single PCRF to these compounds based on the PCRF for ethane, with the addition of a correction factor for the presence of sulfur atoms (Mockel, 1976). It is important to note that Mockel (1976) reported that the number of sulfur atoms does not alter the FID response and thus a single factor was used for DMS, DMDS, and DMTS. The LOD for the three sulfide compounds was $20 \mathrm{ppt}$ for the analysis of $1350 \mathrm{~cm}^{3}$ from the canister (Meinardi et al., 2013).

A direct intercomparison between the PTR-ToF-MS and GC-FID methods was performed for DMS/DMDS using a $1: 100$ with dilution and a $1: 7$ dilution of the certified gas cylinder, as well as sampling a mixture of DMS ( $\sim 21 \mathrm{ppb})$ and DMDS ( $\sim 20 \mathrm{ppb})$ generated using the dynamic injection system. A separate experiment was performed for DMTS, using the dynamic injection system $(\sim 22 \mathrm{ppb})$. Mixing ratios of DMS, DMDS, and DMTS analyzed by GC-FID immediately after sampling were generally in good agreement with the values reported by the PTR-ToF-MS within experimental errors as seen in Fig. 3.

The stability of the three sulfides in the water-doped canisters was also investigated. The study was performed by analyzing the canisters the same day of the standard sample collection and again after 1 week. First, the outflow of the dynamic injection system for all three sulfides was collected in two separate canisters with one canister analyzed on the same day, while the second was stored at room temperature for 1 week. Results are shown in Fig. 4, as the percentage of the mixing ratios measured after 1 week to that on the first day. Recoveries ranged from 53 to $68 \%$ for OSCs generated using the dynamic injection system. This could be due to two factors: the canisters might not have had the exact same initial concentration, and/or the presence of cyclohexane used in generating the calibration mixtures may induce artifacts in the canister.

A second set of tests made using direct gas-phase standards (certified gas cylinder for DMS and DMDS and the permeation tube for DMTS) shows much better recoveries, ranging from 85 to $92 \%$. However, in all tests, the presence of DMDS was observed in the DMTS-doped canister analyzed after 1 week, suggesting that DMTS decomposes on surfaces to yield DMDS. Dimethyl disulfide was also seen as an impurity in the DMTS generated with the permeation tube by PTR-ToF-MS and is likely due to reaction in the permeation tube.

Methanethiol proved to be a challenging compound to analyze using the offline canister/GC-FID approach. A $1.5 \pm 0.02 \mathrm{ppm}$ mixture of the pure gas-phase standard in dry synthetic air was prepared in the laboratory and analyzed via the conventional method using the usual electropolished stainless steel canister without water added prior to sampling. The resulting FID chromatogram (Fig. 5a) shows no MTO but instead a significant peak for dimethyl sulfoxide (DMSO; $\left(\mathrm{CH}_{3}\right)_{2} \mathrm{SO}$ ) and DMDS. The presence of acetone was always observed as an impurity in those samples. Interestingly, when 18-20 Torr water was added to the canister prior addition of MTO mixture the DMSO/DMDS ratio was reversed (Fig. 5b), with a higher contribution from DMDS than DMSO. This water-doped canister was re-analyzed after $24 \mathrm{~h}$, and the DMSO peak vanished, while the DMDS peak increased (Fig. 5c). To the authors' knowledge, this is the first time that DMSO has been observed as an artifact from MTO sampling. Conversion of MTO into DMDS has been previously reported to occur on surfaces, such as old SilcoCan canisters ( $>6$ years old), due to possible cracks on the inert coating of the canister that exposed the metal surface (Khan et al., 2012), various solid sorbents (Katoh et al., 1995; Bashkova et al., 2003; Lestremau et al., 2004; Andersen et al., 2012; Hansen et al., 2012b), and on solid-phase microex- 


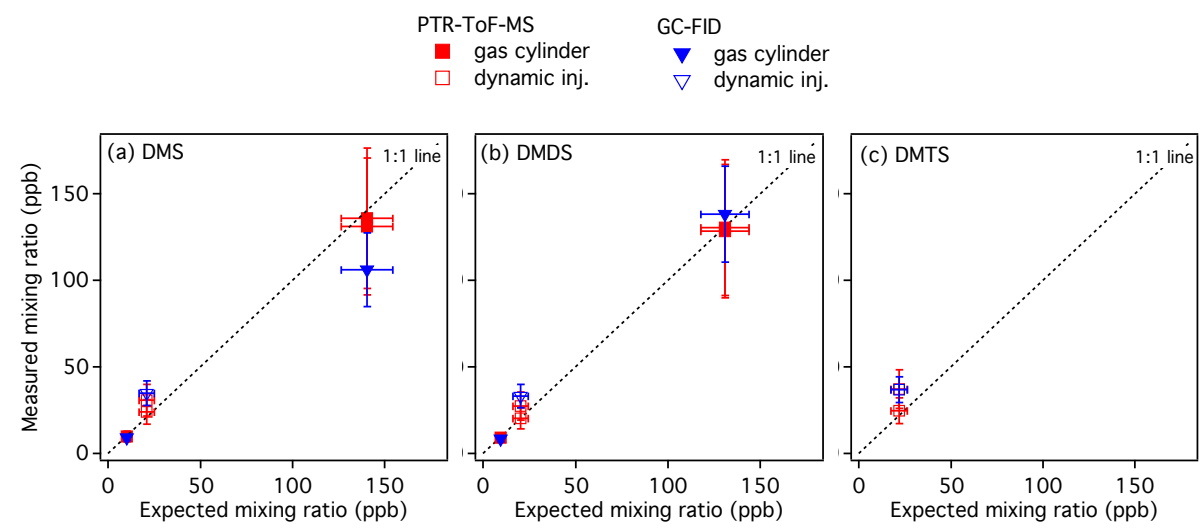

Figure 3. Comparison of quantification of DMS, DMDS, and DMTS using GC-FID (blue markers) and PTR-ToF-MS (red markers). Standards were sampled from either dilutions of a certified gas cylinder (DMS and DMDS; filled symbol) and/or from the dynamic injection system (DMS, DMDS, and DMTS; open symbols). Errors on the mixing ratios measured by the GC-FID method were taken as the $95 \%$ confidence interval $( \pm 20 \%)$ as reported by Simpson et al. (2001) and errors on the mixing ratios measured by the PTR-ToF-MS were taken as $\pm 30 \%$ corresponding to the day-to-day instrument variation. The $1: 1$ line corresponds to the line of perfect agreement between the mixing ratios measured by either the PTR-ToF-MS or the GC-FID and the expected value. The errors bars for the expected mixing ratios after dilution were estimated as $\pm 10 \%(2 \sigma)$ for the DMS/DMDS gas cylinder and as $\pm 20 \%(2 \sigma)$ for the mixtures from the dynamic injection system, based on error propagation analysis.

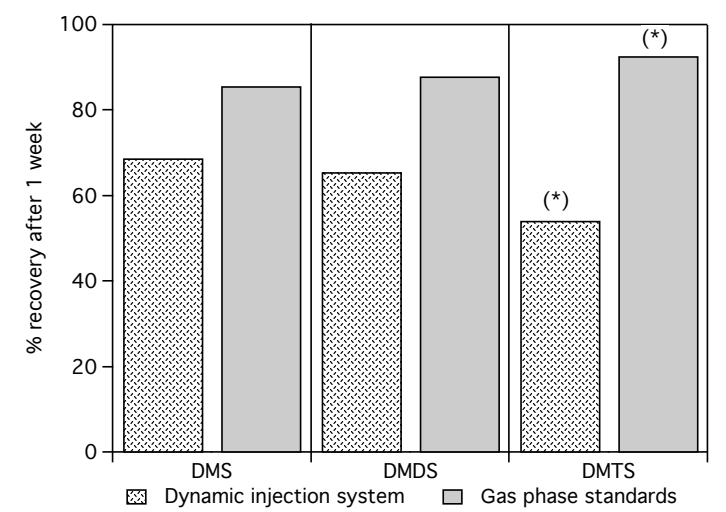

Figure 4. Recovery of DMS, DMDS, and DMTS in electropolished stainless steel canisters after 1 week. Data include measurements made from the dynamic injection system (mottled bars; [DMS] $21 \mathrm{ppb}$; [DMDS] 20 ppb; [DMTS] 33 ppb) and from a gas-phase source (gray bars; [DMS] $140 \mathrm{ppb}$; [DMDS] $\sim 131 \mathrm{ppb}$; [DMTS] undetermined). The asterisks correspond to DMTS samples where DMDS was observed in the canister after 1 week, suggesting that DMTS decomposed on the surface of the canister.

traction fibers (Haberhauer-Troyer et al., 1999; Lestremau et al., 2004). The presence of metal ions and/or a thermal oxidation was suspected to be the source responsible for the reaction. The mechanism of formation of DMSO is not known but may involve the reaction of MTO with the metal oxide surface whose catalytic sites become covered when water is present in the canister.

A new mixture of $1.8 \pm 0.02 \mathrm{ppm}$ MTO was made in a glass sampling vessel instead of a stainless steel canister and analyzed by GC-FID immediately. Results are shown in Fig. 6a for a dry mixture. A significant amount of DMDS is still present but MTO can now be observed in the chromatogram. The ratio of the MTO peak area to that of DMDS was 0.65 . Because no conversion of MTO to DMDS in the glass bulb was observed using PTR-ToF-MS, it is likely that the short time $(<1 \mathrm{~min})$ the sample stays in the stainless steel pre-concentration system (loop and transfer tubing) was enough to allow chemistry to convert some of the MTO into DMDS. To test this hypothesis, a higher mixing ratio of MTO in dry synthetic air was prepared and analyzed without the pre-concentration step, reducing the contact time of the sample in the sampling unit to about $10 \mathrm{~s}$ before injection (in this case only $10 \mathrm{~mL}$ of the sample could be analyzed). The resulting chromatogram (Fig. 6b) shows that while DMDS is still present, the ratio of the MTO peak area to that for DMDS is now $\sim 7.5$, about an order of magnitude larger. Devai and Delaune (1994) previously observed that water influenced the stability of MTO in a glass sampling bulb, with significant losses of MTO within the first hour in moist air. This observation strongly suggests that avoiding metal in sampling systems may not be sufficient for accurate measurement of MTO. Given these issues with surface reactions of MTO, PTR-ToF-MS is the preferred analytical approach for this compound.

\subsection{Application to a complex high-emission source}

Sources of OSCs in urban and rural areas include those of non-marine origin such as human breath (Tonzetic, 1971; Taucher et al., 1996; Van den Velde et al., 2008, 2009), agricultural activities, and pet waste (Burnett, 1969; Williams et 

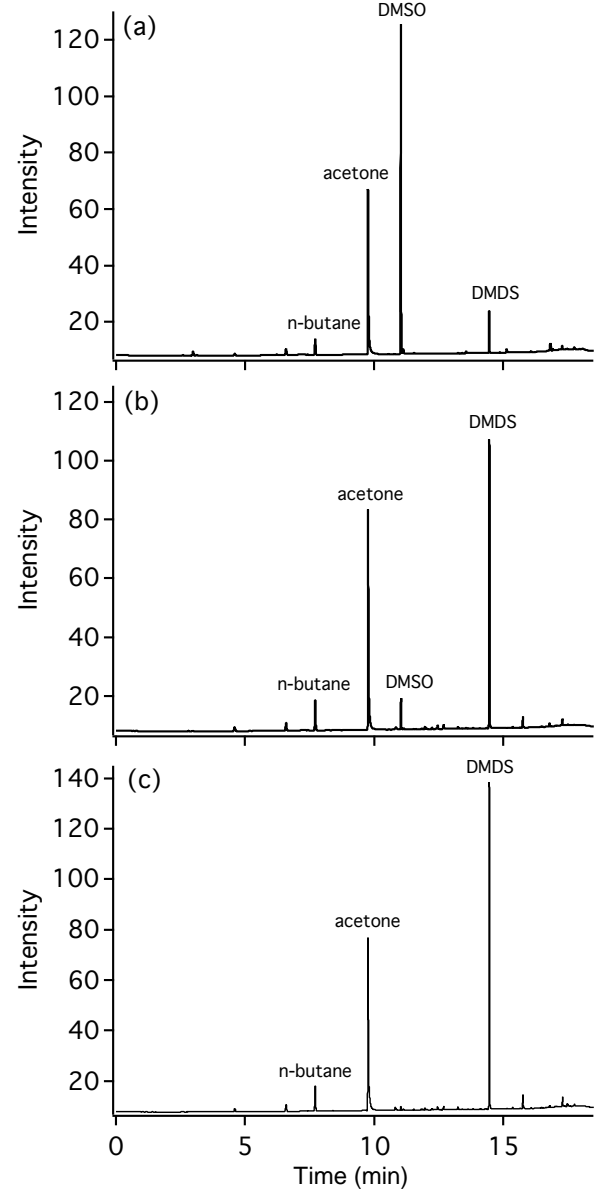

Figure 5. GC-FID chromatograms from the analysis of stainless steel canisters containing pure MTO standard mixtures prepared in the laboratory (a) under dry conditions $([\mathrm{MTO}]=1.49 \mathrm{ppm})$, (b) with water present in the canister $([\mathrm{MTO}]=1.39 \mathrm{ppm})$, and (c) under the same conditions as (b) except the canister was analyzed $24 \mathrm{~h}$ later.

al., 1999; Filipy et al., 2006; Kim et al., 2007; Shaw et al., 2007; Trabue et al., 2008; Feilberg et al., 2010; Meinardi et al., 2013), as well as household biowaste (Mayrhofer et al., 2006; Papurello et al., 2012; Zhang et al., 2013). In this study, the two sampling and analysis methods, PTR-ToF-MS and GC-FID, were applied to the investigation of organosulfur emissions from bins in a suburban location where most of the waste is from pets. This represents a complex mixture that provides a more realistic test of the applicability of these techniques to ambient air and sources than the relatively controlled laboratory samples described above. A typical mass spectrum of a bin sample is presented in Fig. S7a. There are clearly many compounds in the headspace of the bins, illustrating the difficulty of assigning all of the peaks based on the PTR-ToF-MS alone (Table S1 in the Supplement). However, peaks due to DMS and DMDS were clearly identified and confirmed by GC-FID measurements. A peak at $m / z 49$
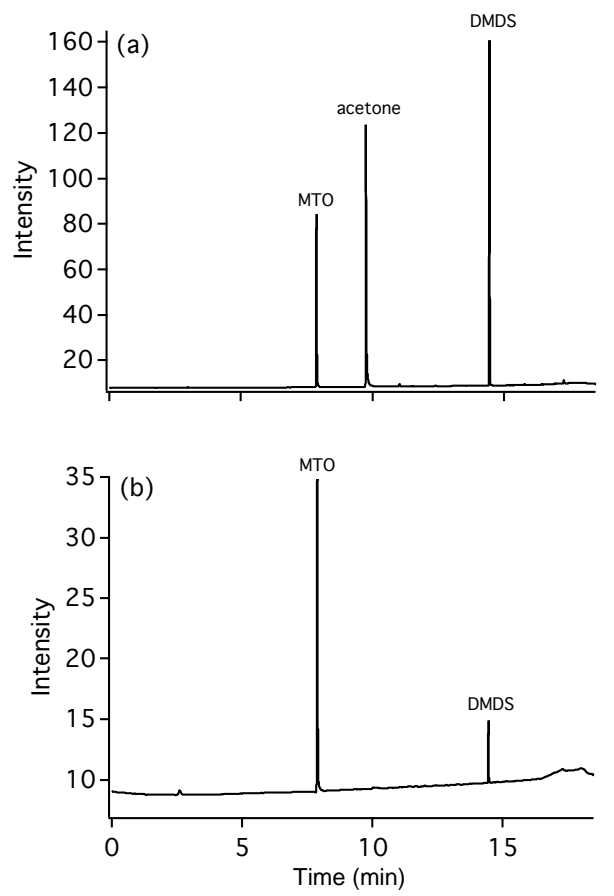

Figure 6. GC-FID chromatograms from the analysis of a glass sampling vessel containing pure MTO standard mixtures prepared in the laboratory. Analyses were performed via (a) the conventional pre-concentration method $([\mathrm{MTO}]=1.80 \mathrm{ppm})$ and $(\mathbf{b})$ via a fast injection method $([\mathrm{MTO}]=12 \mathrm{ppm})$.

was also present in the PTR-ToF-MS spectra, which corresponds to MTO. Positive identification and quantification were based on accurate mass determination along with the ratios of the different fragments defined for the standards. In addition, because DMTS shares common ions with DMDS $(m / z$ 79) and MTO $(m / z 49)$, a positive identification of DMTS was recorded only if nominal masses $m / z 127$ and $\mathrm{m} / z 81$ (excluding the isotopic peak from $m / z$ 79) were both present, and the ratio of $m / z 79$ to 95 was different than that observed for the DMDS standard, suggesting an additional contribution for $m / z 79$.

DMS and DMDS were clearly identified in all samples by PTR-ToF-MS and GC-FID, while DMTS was only detected in the canister samples. It is important to note that the peak at $m / z 79$ observed in all bin samples was exclusively from the DMDS $\mathrm{CH}_{3} \mathrm{SS}^{+}$fragment, as shown in Fig. S7b. No evidence for DMSO or benzene was observed in any bin samples with PTR-ToF-MS, as indicated by the absence of peaks at $m / z 79.0218$ and 79.0548, respectively. Due to sampling and analysis artifacts described above, MTO was only observed in the PTR-ToF-MS analysis. Mixing ratios of all four OSCs measured using PTR-ToF-MS and offline canisters/GC-FID are presented in Table 2.

As can be seen in Fig. 7a and Table 2, DMDS mixing ratios measured by GC-FID (ranging from 14 to $350 \mathrm{ppb}$ ) were systematically higher compared to the PTR-ToF-MS measure- 
Table 2. Results from source samples - intercomparison between PTR-ToF-MS and GC-FID analysis ${ }^{\mathrm{a}}$.

\begin{tabular}{|c|c|c|c|c|c|c|c|c|c|}
\hline \multirow{2}{*}{$\begin{array}{l}\text { Bin } \\
\text { no. }\end{array}$} & \multirow{2}{*}{$\begin{array}{l}\text { Waste weight } \\
\text { and } \mathrm{Vol}_{\text {bin }} \mathrm{b}\end{array}$} & \multicolumn{2}{|c|}{ DMS (ppb) } & \multicolumn{2}{|c|}{ DMDS $(p p b)$} & \multicolumn{2}{|c|}{ DMTS $(p p b)$} & \multicolumn{2}{|c|}{ MTO (ppb) } \\
\hline & & GC-FID & PTR-ToF-MS & GC-FID & PTR-ToF-MS & GC-FID & PTR-ToF-MS & GC-FID & PTR-ToF-MS \\
\hline 1 & & $61 \pm 12$ & $47 \pm 14$ & $350 \pm 70$ & $165 \pm 50$ & $33 \pm 7$ & n.d. & n.d. & $267 \pm 80$ \\
\hline $2^{c}$ & $8 \mathrm{lb}$ & - & $7 \pm 2$ & - & $20 \pm 6$ & - & n.d. & n.d. & $33 \pm 10$ \\
\hline $3^{d}$ & $135 \mathrm{~L}$ bin & $\begin{array}{c}15 \pm 3 \text { and } \\
14 \pm 3\end{array}$ & $10 \pm 3$ & $\begin{array}{c}84 \pm 17 \text { and } \\
64 \pm 13\end{array}$ & $27 \pm 8$ & $\begin{array}{c}2 \pm 0.4 \text { and } \\
5 \pm 1\end{array}$ & n.d. & n.d. & $59 \pm 18$ \\
\hline 4 & & $18 \pm 4$ & $13 \pm 4$ & $119 \pm 23$ & $44 \pm 13$ & $15 \pm 3$ & n.d. & n.d. & $111 \pm 33$ \\
\hline 5 & $\begin{array}{c}1 \mathrm{lb}, \\
135 \mathrm{~L} \mathrm{bin}\end{array}$ & $1.3 \pm 0.3$ & $1.2 \pm 0.4$ & $14 \pm 3$ & $1.5 \pm 0.5$ & $8 \pm 2$ & n.d. & n.d. & $33 \pm 10$ \\
\hline $6^{c}$ & $1 \mathrm{lb}$ & - & $23 \pm 7$ & - & $23 \pm 7$ & - & n.d. & n.d. & $\mathrm{e}$ \\
\hline 7 & $21 \mathrm{~L}$ bin & $19 \pm 4$ & $15 \pm 5$ & $120 \pm 24$ & $26 \pm 8$ & $188 \pm 38$ & n.d. & n.d. & $722 \pm 217$ \\
\hline 8 & & $15 \pm 3$ & $12 \pm 4$ & $97 \pm 19$ & $16 \pm 5$ & $145 \pm 29$ & n.d. & n.d. & $718 \pm 215$ \\
\hline 9 & $3 \mathrm{lb}$ & $11 \pm 2$ & $7 \pm 2$ & $27 \pm 5$ & $6 \pm 2$ & $33 \pm 7$ & n.d. & n.d. & $106 \pm 32$ \\
\hline 10 & $135 \mathrm{~L}$ bin & $11 \pm 2$ & $7 \pm 2$ & $26 \pm 5$ & $6 \pm 2$ & $27 \pm 5$ & n.d. & n.d. & $127 \pm 38$ \\
\hline 11 & & $7 \pm 1$ & $5 \pm 2$ & $23 \pm 5$ & $4 \pm 1$ & $34 \pm 7$ & n.d. & n.d. & $82 \pm 25$ \\
\hline
\end{tabular}

a Errors were taken as $\pm 20 \%$ for the GC-FID values (Simpson et al., 2001) and $\pm 30 \%$ for the PTR-ToF-MS values (day-to-day instrument variation).

b The volume of the bin $\left(\mathrm{Vol}_{\text {bin }}\right)$ was determined via two methods: measuring the weight of the container after filling it with water and by measuring the time

to fill the bin with water at the flow rate of $41 \mathrm{~L} \mathrm{~min}^{-1}$.

c Canister measurements were not available for bins 2 and 6.

d Two successive canisters were sampled for bin 3 .

e The signal for MTO saturated the detector.

n.d.: not detected.

Table 3. Emission rates from bins for DMS, DMDS, and MTO determined by PTR-ToF-MS in molecules $\mathrm{cm}^{-3} \mathrm{~s}^{-1}$ a

\begin{tabular}{|c|c|c|c|c|}
\hline Bin no. & $\begin{array}{c}\text { Waste } \\
\text { weight and } \\
\text { bin volume }\end{array}$ & $\begin{array}{c}\text { DMS } \\
\left(\text { molecules } \mathrm{cm}^{-3} \mathrm{~s}^{-1}\right)\end{array}$ & $\begin{array}{c}\text { DMDS } \\
\left(\text { molecules } \mathrm{cm}^{-3} \mathrm{~s}^{-1}\right)\end{array}$ & $\begin{array}{c}\mathrm{CH}_{3} \mathrm{SH} \\
\left(\text { molecules } \mathrm{cm}^{-3} \mathrm{~s}^{-1} \text { ) }\right.\end{array}$ \\
\hline 1 & & $1.32 \times 10^{9}$ & $4.37 \times 10^{9}$ & $7.12 \times 10^{9}$ \\
\hline 2 & $8 \mathrm{lb}$ & $1.35 \times 10^{8}$ & $3.74 \times 10^{8}$ & $6.51 \times 10^{8}$ \\
\hline 3 & $135 \mathrm{~L}$ bin & $2.37 \times 10^{8}$ & $5.74 \times 10^{8}$ & $1.36 \times 10^{9}$ \\
\hline 4 & & $2.92 \times 10^{8}$ & $9.64 \times 10^{8}$ & $2.51 \times 10^{9}$ \\
\hline 5 & $\begin{array}{l}1 \mathrm{lb}, \\
135 \mathrm{~L} \text { bin }\end{array}$ & $2.45 \times 10^{7}$ & $2.78 \times 10^{7}$ & $7.12 \times 10^{8}$ \\
\hline 6 & & $6.36 \times 10^{8}$ & $7.16 \times 10^{8}$ & $4.02 \times 10^{10 b}$ \\
\hline 7 & $1 \mathrm{lb}$ & $6.18 \times 10^{8}$ & $1.09 \times 10^{9}$ & $3.01 \times 10^{10}$ \\
\hline 8 & $21 \mathrm{~L}$ bin & $4.85 \times 10^{8}$ & $5.66 \times 10^{8}$ & $2.95 \times 10^{10}$ \\
\hline 9 & & $3.17 \times 10^{8}$ & $2.65 \times 10^{8}$ & $4.83 \times 10^{9}$ \\
\hline 10 & $3 \mathrm{lb}$ & $2.94 \times 10^{8}$ & $2.70 \times 10^{8}$ & $5.18 \times 10^{9}$ \\
\hline 11 & $21 \mathrm{~L}$ bin & $1.88 \times 10^{8}$ & $1.75 \times 10^{8}$ & $3.22 \times 10^{9}$ \\
\hline
\end{tabular}

a Errors on these values are typically $\pm 4 \%$ taken as the $95 \%$ confidence interval.

$\mathrm{b}$ The emission rate for MTO was determined using the beginning of the sampling (from 0 to $10 \mathrm{~min}$ ), where the signal was not saturating the PTR-ToF-MS detector.

ments (ranging from 1.5 to $165 \mathrm{ppb}$ ), with an average factor of two (Fig. 7a). Note that individual measurements may differ by more than this average value as indicated in Table 2 . This is likely due to the presence of MTO and its conversion to DMDS as seen in the studies using individual compounds described earlier. Methanethiol measured by PTR-ToF-MS ranged from 33 to about $720 \mathrm{ppb}$. Thus the excess DMDS measured in the canisters was attributed to the conversion of MTO to DMDS on surfaces.
For DMS, the GC-FID measurements were on average $27 \pm 3 \%$ larger than the PTR-ToF-MS derived mixing ratios. This could be due to differences in sampling: while the PTRToF-MS pulls a constant flow of $150 \mathrm{~cm}^{3} \mathrm{~min}^{-1}$ from the top of the bin, the canister pulls a faster flow in a shorter period of time which could affect the flow dynamics in the bin, thus altering the mixing ratios somewhat.

Lastly, although DMTS was not observed in the PTRToF-MS spectra, this compound was observed by GC-FID. 

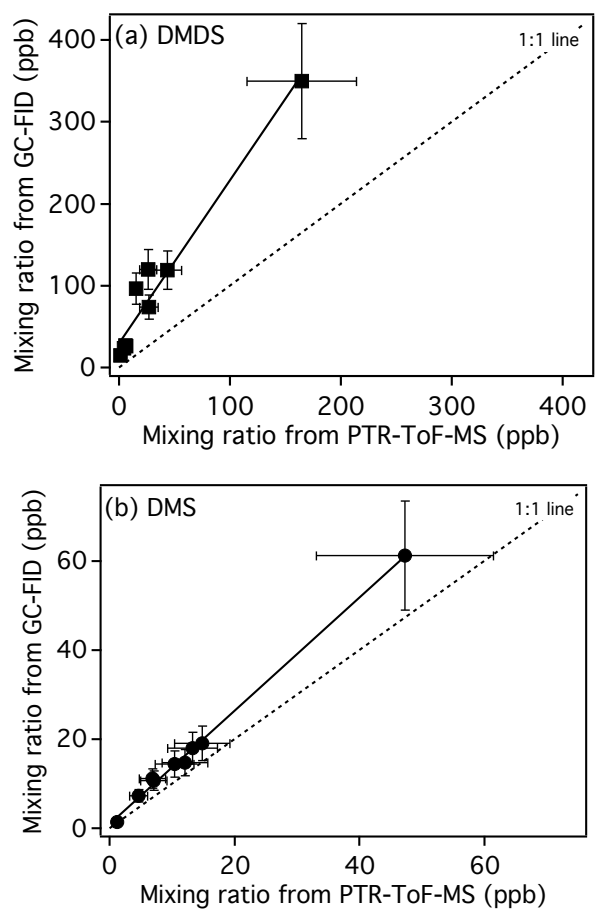

Figure 7. Intercomparison between GC-FID and PTR-ToF-MS measurements of (a) DMDS and (b) DMS from the bin source samples. The dotted lines correspond to the $1: 1$ line (line of perfect agreement) and the black lines correspond to linear regression fits with $y=0.89+1.27 x$ for DMS $\left(r^{2}=0.997\right)$ and $y=29+2.00 x$ for DMDS $\left(r^{2}=0.956\right)$.

It has been previously reported that MTO can be converted to DMTS in the presence of $\mathrm{H}_{2} \mathrm{~S}$ and metals (Chin and Lindsay, 1994). Hydrogen sulfide was also observed in the source sample measured by PTR-ToF-MS at nominal mass $m / z 35$ (exact mass determination was performed to confirm the identity of the compound). Hydrogen sulfide is a relatively difficult compound to quantify by PTR-ToF-MS due to its low proton affinity $\left(705 \mathrm{~kJ} \mathrm{~mol}^{-1}\right)$ (Lide, 1994) so that its signal depends on the relative humidity of the sample (Feilberg et al., 2010; Hansen et al., 2012a; Li et al., 2014). Calibration of $\mathrm{H}_{2} \mathrm{~S}$ was beyond the scope of this study, but the signal observed in the mass spectra was normalized to its highest value to see whether it was correlated with the DMTS signal. As seen in Fig. 8a, DMTS was the highest for samples no. 7 and 8 , where MTO and $\mathrm{H}_{2} \mathrm{~S}$ were also high. Thus, it is possible that DMTS was formed in a reaction of MTO with $\mathrm{H}_{2} \mathrm{~S}$ on the surface of the canister and/or sampling lines rather than being emitted directly from the sample. Figure $8 \mathrm{~b}$ and $\mathrm{c}$ show the corresponding DMS and DMDS normalized mixing ratios, which exhibit a very different pattern. This suggests that DMS and DMDS are not involved in DMTS formation. However, it is noteworthy that DMDS by GC-FID is highest for samples no. 7 and 8 , supporting the reaction of MTO on surfaces as a source of DMDS.
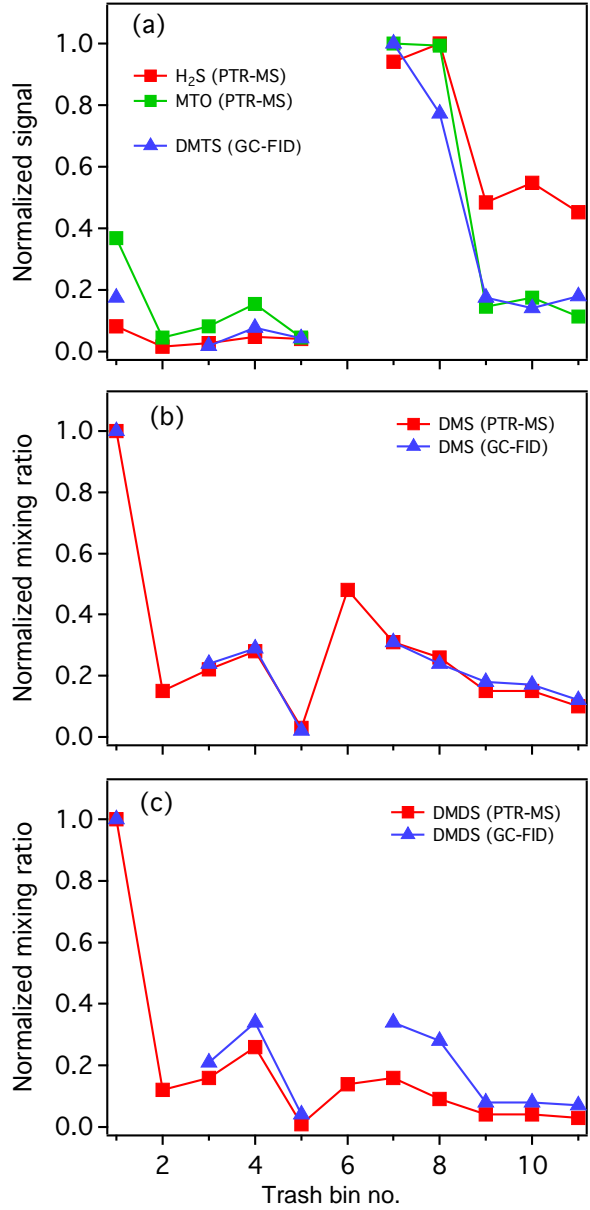

Figure 8. Normalized mixing ratios and signals obtained for all four organosulfur compounds from the source samples including (a) MTO, DMTS, and $\mathrm{H}_{2} \mathrm{~S}$; (b) DMS; and (c) DMDS in different bins. Canister samples were not available for bins 2 and 6 . The lines between symbols of individual bins are simply a visual aid.

To test whether MTO and $\mathrm{H}_{2} \mathrm{~S}$ react to form DMTS, a separate set of experiments was conducted where the outflow of a permeation device containing gas-phase MTO was mixed with the outflow of a second permeation device containing gas-phase $\mathrm{H}_{2} \mathrm{~S}$ and analyzed by both PTR-ToF-MS and GC-FID. Figure 9 shows the results of the analysis for both techniques. While the PTR-ToF-MS only shows a peak at nominal masses $m / z 35$ and $m / z 49$ characteristic of $\mathrm{H}_{2} \mathrm{~S}$ and MTO protonated ions, respectively, the canister GC-FID measurements show that DMTS is formed when both MTO and $\mathrm{H}_{2} \mathrm{~S}$ are present. In short, it is clear that MTO and $\mathrm{H}_{2} \mathrm{~S}$ react on metal surfaces to form DMTS and that MTO alone forms DMDS.

Lastly, because PTR-ToF-MS allows sampling in real time, it was possible to determine emission rates for DMS, DMDS and MTO directly emitted from the bins. Between each sample, the bins were aired out, and a new waste sample was introduced. The lid on the bin was then closed and the 
(a) $\mathrm{H}_{2} \mathrm{~S}$ alone

(b) MTO alone

(c) $\mathrm{MTO}+\mathrm{H}_{2} \mathrm{~S}$
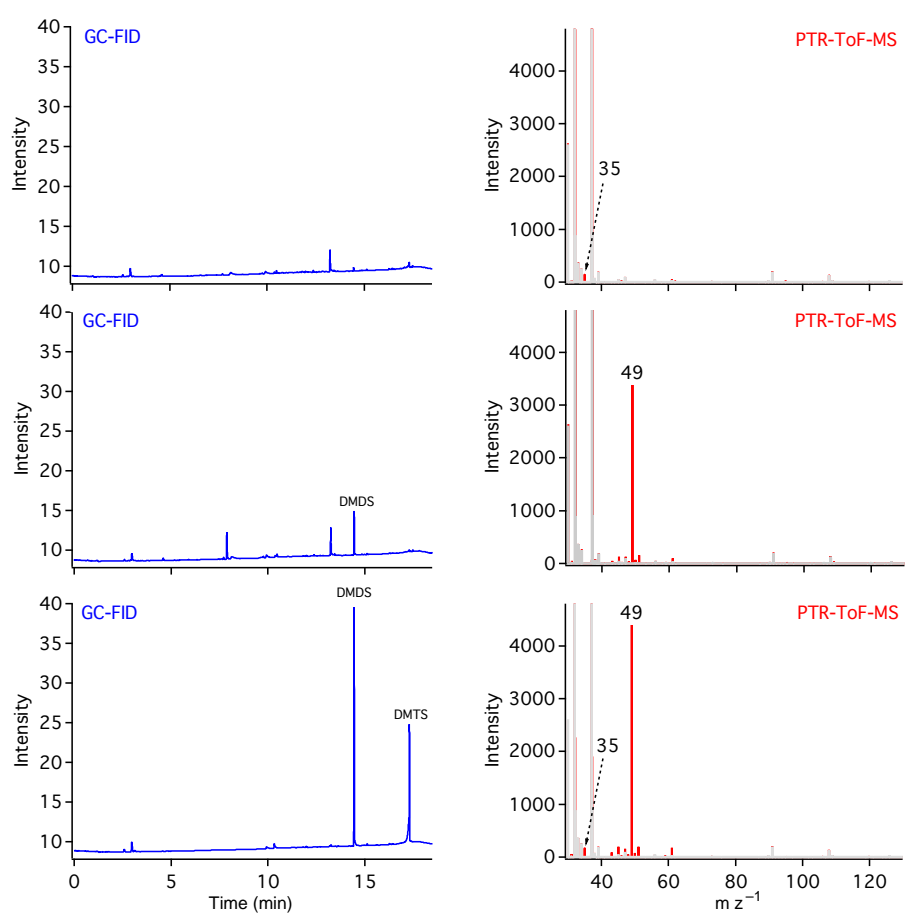

Figure 9. Left panel: GC-FID chromatograms of (a) the $\mathrm{H}_{2} \mathrm{~S}$ standard in dry synthetic air ( $\left.\sim 460 \mathrm{ppb}\right)$, (b) the MTO standard in dry synthetic air ( $\sim 816 \mathrm{ppb}$ ), and (c) a mixture of the MTO and $\mathrm{H}_{2} \mathrm{~S}$ standard ([MTO] $\sim 408 \mathrm{ppb}$; $\left[\mathrm{H}_{2} \mathrm{~S}\right] \sim 230 \mathrm{ppb}$ ) sampled using a water-doped stainless steel canister. Right panel: Corresponding PTR-ToF-MS spectrum for each sample.

increase in the OSC mixing ratios in the headspace was measured as a function of time. Results are presented in Table 3. Those values were integrated into a 3-D airshed model in a separate study to evaluate the importance of such continental sources on the formation of the OSC oxidation products methanesulfonic acid and sulfuric acids in a large coastal urban area (Perraud et al., 2015). In that study, there were a number of potential sources of atmospheric OSCs that have not been yet quantified, and these techniques could be useful in the future.

In conclusion, gas-phase OSCs are challenging to measure, especially in complex mixtures characteristic of air. While PTR-ToF-MS provides real-time sampling capability, fragmentation of parent ions in such mixtures dictates caution in assigning peaks to specific compounds without additional data such as GC-FID. In addition, species such as $\mathrm{H}_{2} \mathrm{~S}$ that have proton affinities close to that of water are not as easily measured due to the dependence on relative humidity. Canister sampling with GC-FID provides excellent sensitivity but can suffer from reactions on metal canister and analysis surfaces. The latter is also an issue if metal sampling lines are used in conjunction with PTR-ToF-MS.

\section{The Supplement related to this article is available online at doi:10.5194/amt-9-1325-2016-supplement.}

Acknowledgements. We are grateful for funding from the National Science Foundation (grant no. 1443140) and the NSF Major Research Instrumentation (MRI) program (grant no. 0923323) for the PTR-ToF-MS. We would also like to thank A. Ezell Smith, M. L. Dawson, B. Love, G. Liu and M. Pitts for their technical assistance during the bin measurements, C. Murray for the pure MTO gas standard, and J. de Grosbois for helpful discussions.

Edited by: G. Phillips

\section{References}

Andersen, K. B., Hansen, M. J., and Feilberg, A.: Minimisation of artefact formation of dimethyl disulphide during sampling and analysis of methanethiol in air using solid sorbent materials, J. Chromatogr. A, 1245, 24-31, 2012.

Andreae, M. O.: Ocean-Atmosphere interactions in the global biogeochemical sulfur cycle, Mar. Chem., 30, 1-29, 1990.

Andreae, M. O., Ferek, R. J., Bermond, F., Byrd, K. P., Engstrom, R. T., Hardin, S., Houmere, P. D., Lemarrec, F., Raemdonck, H., and Chatfield, R. B.: Dimethyl sulfide in the marine atmosphere, J. Geophys. Res., 90, 2891-2900, 1985.

Andreae, T. W., Andreae, M. O., Bingemer, H. G., and Leck, C.: Measurements of dimethyl sulfide and $\mathrm{H}_{2} \mathrm{~S}$ over the western north Atlantic and the tropical Atlantic, J. Geophys. Res., 98, 23389-23396, 1993.

Aneja, V. P.: Natural sulfur emissions into the atmosphere, J. Air Waste Manage., 40, 469-476, 1990. 
Aprea, E., Biasioli, F., Carlin, S., Versini, G., Mark, T. D., and Gasperi, F.: Rapid white truffle headspace analysis by proton transfer reaction mass spectrometry and comparison with solidphase microextraction coupled with gas chromatography/mass spectrometry, Rapid Commun. Mass Sp., 21, 2564-2572, 2007.

Arnold, S. T., Thomas, J. M., and Viggiano, A. A.: Reactions of $\mathrm{H}_{3} \mathrm{O}^{+}\left(\mathrm{H}_{2} \mathrm{O}\right)_{(n)}$ and $\mathrm{H}^{+}\left(\mathrm{H}_{2} \mathrm{O}\right)_{(n)}\left(\mathrm{CH}_{3} \mathrm{COCH}_{3}\right)_{(m)}$ with $\mathrm{CH}_{3} \mathrm{SCH}_{3}$, Int. J. Mass Spectrom., 180, 243-251, 1998.

Barnes, I., Bastian, V., and Becker, K. H.: Kinetics and mechanisms of the reaction of $\mathrm{OH}$ radicals with dimethyl sulfide, Int. J. Chem. Kinet., 20, 415-431, 1988.

Barnes, I., Becker, K. H., and Mihalopoulos, N.: An FTIR product study of the photooxidation of dimethyl disulfide, J. Atmos. Chem., 18, 267-289, 1994.

Barnes, I., Hjorth, J., and Mihalopoulos, N.: Dimethyl sulfide and dimethyl sulfoxide and their oxidation in the atmosphere, Chem. Rev., 106, 940-975, 2006.

Bashkova, S., Bagreev, A., and Bandosz, T. J.: Adsorption/oxidation of $\mathrm{CH}_{3} \mathrm{SH}$ on activated carbons containing nitrogen, Langmuir, 19, 6115-6121, 2003.

Bates, T. S., Lamb, B. K., Guenther, A., Dignon, J., and Stoiber, R. E.: Sulfur emissions to the atmosphere from natural sources, J. Atmos. Chem., 14, 315-337, 1992.

Berglund, M. and Wieser, M. E.: Isotopic compositions of the elements 2009 (IUPAC Technical Report), Pure Appl. Chem., 83, 397-410, 2011.

Berndt, T. and Richters, S.: Products of the reaction of $\mathrm{OH}$ radicals with dimethyl sulphide in the absence of $\mathrm{NO}_{x}$ : Experiment and simulation, Atmos. Environ., 47, 316-322, 2012.

Berresheim, H., Andreae, M. O., Ayers, G. P., Gillett, R. W., Merrill, J. T., Davis, V. J., and Chameides, W. L.: Airborne measurements of dimethylsulfide, sulfur dioxide and aerosol Ions over the southern ocean of Australia, J. Atmos. Chem., 10, 341-370, 1990.

Beyersdorf, A. J., Blake, D. R., Swanson, A., Meinardi, S., Rowland, F. S., and Davis, D.: Abundances and variability of tropospheric volatile organic compounds at the South Pole and other Antarctic locations, Atmos. Environ., 44, 4565-4574, 2010.

Blake, D. R., Smith, T. W., Chen, T. Y., Whipple, W. J., and Rowland, F. S.: Effects of biomass burning on summertime nonmethane hydrocarbon concentrations in the canadian wetlands, J. Geophys. Res., 99, 1699-1719, 1994.

Blake, R. S., Monks, P. S., and Ellis, A. M.: Proton-transfer reaction mass spectrometry, Chem. Rev., 109, 861-896, 2009.

Blunden, J., Aneja, V. P., and Lonneman, W. A.: Characterization of non-methane volatile organic compounds at swine facilities in eastern North Carolina, Atmos. Environ., 39, 6707-6718, 2005.

Brown, P., Watts, P., Mark, T. D., and Mayhew, C. A.: Proton transfer reaction mass spectrometry investigations on the effects of reduced electric field and reagent ion internal energy on product ion branching ratios for a series of saturated alcohols, Int. J. Mass Spectrom., 294, 103-111, 2010.

Buhr, K., van Ruth, S., and Delahunty, C.: Analysis of volatile flavour compounds by proton-transfer reaction mass spectrometry: Fragmentation patterns and discrimination between isobaric and isomeric compounds, Int. J. Mass Spectrom., 221, 1-7, 2002.

Burnett, W. E.: Air pollution from animal wastes - Determination of malodors by gas chromatographic and organoleptic techniques, Environ. Sci. Technol., 3, 744-749, 1969.
Bzdek, B. R. and Johnston, M. V.: New particle formation and growth in the troposphere, Anal. Chem., 82, 7871-7878, 2010.

Capaldo, K. P. and Pandis, S. N.: Dimethylsulfide chemistry in the remote marine atmosphere: Evaluation and sensitivity analysis of available mechanisms, J. Geophys. Res., 102, 23251-23267, 1997.

Cappellin, L., Probst, M., Limtrakul, J., Biasioli, F., Schuhfried, E., Soukoulis, C., Mark, T. D., and Gasperi, F.: Proton transfer reaction rate coefficients between $\mathrm{H}_{3} \mathrm{O}^{+}$and some sulphur compounds, Int. J. Mass Spectrom., 295, 43-48, 2010.

Chin, H. W. and Lindsay, R. C.: Ascorbate and transition-metal mediation of methanethiol oxidation to dimethyl disulfide and dimethyl trisulfide, Food Chem., 49, 387-392, 1994.

Christian, T. J., Kleiss, B., Yokelson, R. J., Holzinger, R., Crutzen, P. J., Hao, W. M., Shirai, T., and Blake, D. R.: Comprehensive laboratory measurements of biomass-burning emissions: 2. First intercomparison of open-path FTIR, PTRMS, and GC- MS/FID/ECD, J. Geophys. Res., 109, D02311, doi:02310.01029/02003JD003874, 2004.

Colman, J. J., Swanson, A. L., Meinardi, S., Sive, B. C., Blake, D. R., and Rowland, F. S.: Description of the analysis of a wide range of volatile organic compounds in whole air samples collected during PEM-Tropics A and B, Anal. Chem., 73, 37233731, 2001.

Crutzen, P. J., Williams, J., Poschl, U., Hoor, P., Fischer, H., Warneke, C., Holzinger, R., Hansel, A., Lindinger, W., Scheeren, B., and Lelieveld, J.: High spatial and temporal resolution measurements of primary organics and their oxidation products over the tropical forests of Surinam, Atmos. Environ., 34, 1161-1165, 2000.

Davison, B. and Hewitt, C. N.: Elucidation of the tropospheric reactions of biogenic sulfur species from a field measurement campaign in New Scotland, Chemosphere, 28, 543-557, 1994.

Dawson, M. L., Varner, M. E., Perraud, V., Ezell, M. J., Gerber, R. B., and Finlayson-Pitts, B. J.: Simplified mechanism for new particle formation from methanesulfonic acid, amines and water via experiments and ab initio calculations, P. Natl. Acad. Sci. USA, 109, 18719-18724, 2012.

de Bruyn, W. J., Harvey, M., Cainey, J. M., and Saltzman, E. S.: DMS and $\mathrm{SO}_{2}$ at Baring Head, New Zealand: Implications for the yield of $\mathrm{SO}_{2}$ from DMS, J. Atmos. Chem., 41, 189-209, 2002.

de Gouw, J. and Carsten, W.: Measurements of volatile organic compounds in the Earth's atmosphere using proton-transferreaction mass spectrometry, Mass Spectrom. Rev., 26, 223-257, 2007.

Devai, I. and Delaune, R. D.: Changes in reduced gaseous sulfurcompounds collected in glass gas sampling bulbs, Anal. Lett., 27, 2403-2411, 1994.

Dockery, D. W., Pope, C. A., Xu, X. P., Spengler, J. D., Ware, J. H., Fay, M. E., Ferris, B. G., and Speizer, F. E.: An Association between air-pollution and mortality in six United-States cities, New Engl. J. Med., 329, 1753-1759, 1993.

Feilberg, A., Liu, D. Z., Adamsen, A. P. S., Hansen, M. J., and Jonassen, K. E. N.: Odorant emissions from intensive pig production measured by online proton-transfer-reaction mass spectrometry, Environ. Sci. Technol., 44, 5894-5900, 2010. 
Filipy, J., Rumburg, B., Moount, G., Westberg, H., and Lamb, B.: Identification and quantification of volatile organic compounds from a dairy, Atmos. Environ., 40, 1480-1494, 2006.

Finlayson-Pitts, B. J. and Pitts Jr., J. N.: Chemistry of the Upper and Lower Atmosphere - Theory, Experiments, and Applications, Academic Press, San Diego, CA, USA, 969 pp., 2000.

Freshour, N. A., Carlson, K. K., Melka, Y. A., Hinz, S., Panta, B., and Hanson, D. R.: Amine permeation sources characterized with acid neutralization and sensitivities of an amine mass spectrometer, Atmos. Meas. Tech., 7, 3611-3621, doi:10.5194/amt7-3611-2014, 2014.

Geng, C. M. and Mu, Y. J.: Carbonyl sulfide and dimethyl sulfide exchange between trees and the atmosphere, Atmos. Environ., 40, 1373-1383, 2006.

Goldan, P. D., Kuster, W. C., Albritton, D. L., and Fehsenfeld, F. C.: The measurement of natural sulfur emissions from soils and vegetation -3 Sites in the Eastern-United-States revisited, J. Atmos. Chem., 5, 439-467, 1987.

Graus, M., Muller, M., and Hansel, A.: High resolution PTR-TOF: Quantification and formula confirmation of VOC in real time, J. Am. Soc. Mass Spectr., 21, 1037-1044, 2010.

Greaves, J. L. and Roboz, J.: Mass Spectrometry for Novices, Taylor and Francis, Boca Raton, FL, USA, 2013.

Grosjean, D.: Photooxidation of methyl sulfide, ethyl sulfide and methanethiol, Environ. Sci. Technol., 18, 460-468, 1984.

Gueneron, M., Erickson, M. H., VanderScheldn, G. S., and Jobson, B. T.: PTR-MS fragmentation patterns of gasoline hydrocarbons, Int. J. Mass Spectrom., 379, 97-109, 2015.

Guo, H., Simpson, I. J., Ding, A. J., Wang, T., Saunders, S. M., Wang, T. J., Cheng, H. R., Barletta, B., Meinardi, S., Blake, D. R., and Rowland, F. S.: Carbonyl sulfide, dimethyl sulfide and carbon disulfide in the Pearl River Delta of southern China: Impact of anthropogenic and biogenic sources, Atmos. Environ., 44, 3805-3813, 2010.

Haberhauer-Troyer, C., Rosenberg, E., and Grasserbauer, M.: Evaluation of solid-phase microextraction for sampling of volatile organic sulfur compounds in air for subsequent gas chromatographic analysis with atomic emission detection, J. Chromatogr. A, 848, 305-315, 1999.

Hallquist, M., Wenger, J. C., Baltensperger, U., Rudich, Y., Simpson, D., Claeys, M., Dommen, J., Donahue, N. M., George, C., Goldstein, A. H., Hamilton, J. F., Herrmann, H., Hoffmann, T., Iinuma, Y., Jang, M., Jenkin, M. E., Jimenez, J. L., Kiendler-Scharr, A., Maenhaut, W., McFiggans, G., Mentel, Th. F., Monod, A., Prévôt, A. S. H., Seinfeld, J. H., Surratt, J. D., Szmigielski, R., and Wildt, J.: The formation, properties and impact of secondary organic aerosol: current and emerging issues, Atmos. Chem. Phys., 9, 5155-5236, doi:10.5194/acp-9-51552009, 2009.

Hansen, M. J., Adamsen, A. P. S., Feilberg, A., and Jonassen, K. E. N.: Stability of odorants from pig production in sampling bags for olfactometry, J. Environ. Qual., 40, 1096-1102, 2011.

Hansen, M. J., Liu, D. Z., Guldberg, L. B., and Feilberg, A.: Application of proton-transfer reaction mass spectrometry to the assessment of odorant removal in a biological air cleaner for pig production, J. Agr. Food Chem., 60, 2599-2606, 2012 a.

Hansen, M. J., Toda, K., Obata, T., Adamsen, A. P. S., and Feilberg, A.: Evaluation of single column trapping/separation and chemiluminescence detection for measurement of methanethiol and dimethyl sulfide from pig production, J. Anal. Methods Chem., 2012, 489239, doi:10.1155/2012/489239, 2012b.

Hansen, M. J., Adamsen, A. P. S., and Feilberg, A.: Recovery of odorants from an olfactometer measured by proton-transfer reaction mass spectrometry, Sensors-Basel, 13, 7860-7871, 2013.

Harris, D. C.: Quantitative chemical analysis, 3rd edn., WH Freeman and Company, New York, USA, 1991.

Hatakeyama, S. and Akimoto, H.: Reactions of $\mathrm{OH}$ radicals with methanethiol, dimethylsulfide and dimethyl disulfide in air, J. Phys. Chem., 87, 2387-23295, 1983.

Hayward, S., Hewitt, C., Sartin, J., and Owen, S.: Performance characteristics and applications of a proton transfer reaction mass spectometer for measuring volatile organic compounds in ambient air, Environ. Sci. Technol., 36, 1554-1560, 2002.

Herbig, J., Muller, M., Schallhart, S., Titzmann, T., Graus, M., and Hansel, A.: On-line breath analysis with PTR-TOF, J. Breath Res., 3, 1-10, 2009.

Hinds, W. C.: Aerosol Technology: Properties, Behavior and Measurement of Airborne Particles, John Wiley \& Sons Inc., New York, USA, 1999.

Hofmann, U., Hofmann, R., and Kesselmeier, J.: Cryogenic trapping of reduced sulfur-compounds using a nafion drier and cotton wadding as an oxidant scavenger, Atmos. Environ., 26, 2445 2449, 1992.

Jardine, K., Yañez-Serrano, A. M., Williams, J., Kunert, N., Jardine, A., Taylor, T., Abrell, L., Artaxo, P., Guenther, A., Hewitt, C. N., House, E., Florentino, A. P., Manzi, A., Higuchi, N., Kesselmeier, J., Behrendt, T., Veres, P. R., Derstroff, B., Fuentes, J. D., Martin, S. T., and Andreae, M. O.: Dimethylsulfide in the Amazon rainforest, Global Biogeochem. Cy., 29, 19-32, 2015.

Jardine, K. J., Henderson, W. M., Huxman, T. E., and Abrell, L.: Dynamic Solution Injection: a new method for preparing pptvppbv standard atmospheres of volatile organic compounds, Atmos. Meas. Tech., 3, 1569-1576, doi:10.5194/amt-3-1569-2010, 2010.

Jordan, A., Haidacher, S., Hanel, G., Hartungen, E., Mark, L., Seehauser, H., Schottkowsky, R., Sulzer, P., and Mark, T. D.: A high resolution and high sensitivity proton-transfer-reaction time-offlight mass spectrometer (PTR-TOF-MS), Int. J. Mass Spec., 286, 122-128, 2009.

Kai, M., Crespo, E., Cristescu, S. M., Harren, F. J. M., Francke, W., and Piechulla, B.: Serratia odorifera: Analysis of volatile emission and biological impact of volatile compounds on Arabidopsis thaliana, Appl. Microbiol. Biot., 88, 965-976, 2010.

Katoh, H., Kuniyoshi, I., Hirai, M., and Shoda, M.: Studies of the oxidation mechanism of sulfur-containing gases on wet activated carbon-fiber, Appl. Catal. B-Environ., 6, 255-262, 1995.

Kesselmeier, J., Meixner, F. X., Hofmann, U., Ajavon, A. L., Leimbach, S., and Andreae, M. O.: Reduced sulfur compound exchange between the atmosphere and tropical tree species in southern Cameroon, Biogeochemistry, 23, 23-45, 1993.

Khan, M. A. H., Whelan, M. E., and Rhew, R. C.: Analysis of low concentration reduced sulfur compounds (RSCs) in air: Storage issues and measurement by gas chromatography with sulfur chemiluminescence detection, Talanta, 88, 581-586, 2012.

Kim, K. H., Choi, G. H., Choi, Y. J., Song, H. N., Yang, H. S., and Oh, J. M.: The effects of sampling materials selection in the collection of reduced sulfur compounds in air, Talanta, 68, 17131719, 2006. 
Kim, K. Y., Ko, H. J., Kim, H. T., Kim, Y. S., Roh, Y. M., Lee, C. M., Kim, H. S., and Kim, C. N.: Sulfuric odorous compounds emitted from pig-feeding operations, Atmos. Environ., 41, 48114818, 2007.

Kim, S., Karl, T., Helmig, D., Daly, R., Rasmussen, R., and Guenther, A.: Measurement of atmospheric sesquiterpenes by proton transfer reaction-mass spectrometry (PTR-MS), Atmos. Meas. Tech., 2, 99-112, doi:10.5194/amt-2-99-2009, 2009.

Koga, S., Nomura, D., and Wada, M.: Variation of dimethylsulfide mixing ratio over the Southern Ocean from $36^{\circ} \mathrm{S}$ to $70^{\circ} \mathrm{S}$, Polar Sci., 8, 306-313, 2014.

Kulmala, M. and Kerminen, V. M.: On the formation and growth of atmospheric nanoparticles, Atmos. Res., 90, 132-150, 2008.

Kulmala, M., Vehkamäki, H., Petäjä, T., Maso, M. D., Lauri, A., Kerminen, V.-M., Birmili, W., and McMurry, P. H.: Formation and growth rates of ultrafine atmospheric particles: a review of observations, Aerosol Science, 35, 143-176, 2004.

Kulmala, M., Kontkanen, J., Junninen, H., Lehtipalo, K., Manninen, H. E., Nieminen, T., Petaja, T., Sipila, M., Schobesberger, S., Rantala, P., Franchin, A., Jokinen, T., Jarvinen, E., Aijala, M., Kangasluoma, J., Hakala, J., Aalto, P. P., Paasonen, P., Mikkila, J., Vanhanen, J., Aalto, J., Hakola, H., Makkonen, U., Ruuskanen, T., Mauldin, R. L., Duplissy, J., Vehkamaki, H., Back, J., Kortelainen, A., Riipinen, I., Kurten, T., Johnston, M. V., Smith, J. N., Ehn, M., Mentel, T. F., Lehtinen, K. E. J., Laaksonen, A., Kerminen, V. M., and Worsnop, D. R.: Direct observations of atmospheric aerosol nucleation, Science, 339, 943-946, 2013.

Kuster, W. C. and Goldan, P. D.: Quantitation of the losses of gaseous sulfur-compounds to enclosure walls, Environ. Sci. Technol., 21, 810-815, 1987.

Lestremau, F., Andersson, F. A. T., and Desauziers, V.: Investigation of artefact formation during analysis of volatile sulphur compounds using solid phase microextraction (SPME), Chromatographia, 59, 607-613, 2004.

Li, R., Warneke, C., Graus, M., Field, R., Geiger, F., Veres, P. R., Soltis, J., Li, S.-M., Murphy, S. M., Sweeney, C., Pétron, G., Roberts, J. M., and de Gouw, J.: Measurements of hydrogen sulfide $\left(\mathrm{H}_{2} \mathrm{~S}\right)$ using PTR-MS: calibration, humidity dependence, inter-comparison and results from field studies in an oil and gas production region, Atmos. Meas. Tech., 7, 3597-3610, doi:10.5194/amt-7-3597-2014, 2014.

Lide, D. R.: Handbook of Chemistry and Physics, 74th edn., CRC Press, Boca Raton, FL, USA, 1994.

Lindinger, W., Hansel, A., and Jordan, A.: On-line monitoring of volatile organic compounds at ppt levels by means of protontransfer reaction mass spectrometry (PTR-MS) medical applications, food control and environmental research, Inter. J. Mass Spectrom., 173, 191-241, 1998.

Maleknia, S. D., Bell, T. L., and Adams, M. A.: PTR-MS analysis of reference and plant-emitted volatile organic compounds, Int. J. Mass Spectrom., 262, 203-210, 2007.

Mayrhofer, S., Mikoviny, T., Waldhuber, S., Wagner, A. O., Innerebner, G., Franke-Whittle, I. H., Märk, T. D., Hansel, A., and Insam, H.: Microbial community related to volatile organic compound (VOC) emission in household biowaste, Environ. Microbiol., 8, 1960-1974, 2006.

Meinardi, S., Simpson, I. J., Blake, N. J., Blake, D. R., and Rowland, F. S.: Dimethyl disulfide (DMDS) and dimethyl sulfide
(DMS) emissions from biomass burning in Australia, Geophys. Res. Lett., 30, 1454, doi:1410.1029/2003GL016967, 2003.

Meinardi, S., Jin, K.-Y., Barletta, B., Blake, D. R., and Vaziri, N. D.: Exhaled breath and fecal volatile organic biomarkers of chronic kidney disease, Biochim. Biophys. Acta, 1830, 25312537, 2013.

Mikoviny, T., Kaser, L., and Wisthaler, A.: Development and characterization of a High-Temperature Proton-Transfer-Reaction Mass Spectrometer (HT-PTR-MS), Atmos. Meas. Tech., 3, 537544, doi:10.5194/amt-3-537-2010, 2010.

Mockel, H. J.: FID response factors for aliphatic sulphur compounds at higher concentration levels, Z. Anal. Chem. Freseniu., 279, 199-202, 1976.

Mockel, H. J. and Weiss, J.: The electron-impact and chemical ionization mass spectra of dimethyltrisulfide, Z. Anal. Chem. Freseniu., 301, 417-425, 1980.

Nguyen, B. C., Bonsang, B., and Gaudry, A.: The role of the ocean in the global atmospheric sulfur cycle, J. Geophys. Res.-Oc. Atm., 88, 903-914, 1983.

Papurello, D., Soukoulis, C., Schuhfried, E., Cappellin, L., Gasperi, F., Silvestri, S., Santarelli, M., and Biasioli, F.: Monitoring of volatile compound emissions during dry anaerobic digestion of the organic fraction of municipal solid waste by proton transfer reaction time-of-flight mass spectrometry, Bioresource Technol., 126, 254-265, 2012.

Passarella, R., Shul, R. J., Keesee, R. G., and Castleman, A. W.: Gas-phase reactions of sulfides, mercaptans, and dimethyl methylphosphonate with ionic species derived from argon and water, Inter. J. Mass Spectrom., 81, 227-233, 1987.

Patroescu, I. V., Barnes, I., Becker, K. H., and Mihalopoulos, N.: FT-IR product study of the $\mathrm{OH}$-initiated oxidation of DMS in the presence of $\mathrm{NO}_{x}$, Atmos. Environ., 33, 25-35, 1999.

Perraud, V., Horne, J. R., Martinez, A., Kalinowski, J., Meinardi, S., Dawson, M. L., Wingen, L. M., Dabdub, D., Blake, D. R., Gerber, R. B., and Finlayson-Pitts, B. J.: The future of airborne sulfur-containing particles in the absence of fossil fuel sulfur dioxide emissions, P. Natl. Acad. Sci. USA, 112, 13514-13519, 2015.

Pope III, C. A. and Dockery, D. W.: Health effects of fine particulate air pollution: Lines that connect, J. Air Waste Manage., 56, 709742, 2006.

Pope III, C. A., Burnett, R. T., Thun, M. J., Calle, E. E., Krewski, D., Ito, K., and Thurston, G. D.: Lung cancer, cardiopulmonary mortality and long-term exposure to fine particulate air pollution, JAMA-J. Am. Med. Assoc., 287, 1132-1141, 2002.

Schuhfried, E., Probst, M., Limtrakul, J., Wannakao, S., Aprea, E., Cappellin, L., Mark, T. D., Gasperi, F., and Biasioli, F.: Sulfides: Chemical ionization induced fragmentation studied with proton transfer reaction mass spectrometry and density functional calculations, J. Mass Spectrom., 48, 367-378, 2013.

Shaw, S. L., Mitloehner, F. M., Jackson, W., Depeters, E. J., Fadel, J. G., Robinson, P. H., Holzinger, R., and Goldstein, A. H.: Volatile organic compound emissions from dairy cows and their waste as measured by proton-transfer-reaction mass spectrometry, Environ. Sci. Technol., 41, 1310-1316, 2007.

Simpson, I. J., Colman, J. J., Swanson, A. L., Bandy, A. R., Thornton, D. C., Blake, D. R., and Rowland, F. S.: Aircraft measurements of dimethyl sulfide (DMS) using a whole air sampling technique, J. Atmos. Chem., 39, 191-213, 2001. 
Skoog, D. A. and Holler, F. J.: Principles of Instrumental Analysis, Thomson Brooks/Cole, Belmont, CA, USA, 2007.

Smith, J. N., Barsanti, K. C., Friedli, H. R., Ehn, M., Kulmala, M., Collins, D. R., Scheckman, J. H., Williams, B. J., and McMurry, P. H.: Observations of aminium salt formation in atmospheric nanoparticles: Implications for aerosol growth, P. Natl. Acad. Sci. USA, 107, 6634-6639, 2010.

Španěl, P. and Smith, D.: Selected ion flow tube studies of the reactions of $\mathrm{H}_{3} \mathrm{O}^{+}, \mathrm{NO}^{+}$, and $\mathrm{O}_{2}^{+}$with some organosulphur molecules, Int. J. Mass Spectrom., 176, 167-176, 1998.

Sulyok, M., Haberhauer-Troyer, C., and Rosenberg, E.: Observation of sorptive losses of volatile sulfur compounds during natural gas sampling, J. Chromatogr. A, 946, 301-305, 2002.

Tani, A., Hayward, S., and Hewitta, C. N.: Measurement of monoterpenes and related compounds by proton transfer reaction-mass spectrometry (PTR-MS), Int. J. Mass Spectrom., 223, 561-578, 2003.

Taucher, J., Hansel, A., Jordan, A., and Lindinger, W.: Analysis of compounds in human breath after ingestion of garlic using proton-transfer-reaction mass spectrometry, J. Agr. Food Chem., 44, 3778-3782, 1996.

Tonzetic. J: Direct gas chromatographic analysis of sulphur compounds in mouth air in man, Arch. Oral Biol., 16, 587-597, 1971.

Trabue, S., Scoggin, K., Mitloehner, F., Li, J., Burns, R., and Xin, H.: Field sampling method for quantifying volatile sulfur compounds from animal feeding operations, Atmos. Environ., 42, 3332-3341, 2008.

Tyndall, G. S. and Ravishankara, A. R.: Atmospheric oxidation of reduced sulfur species, Int. J. Chem. Kinet., 23, 483-527, 1991.

Van den Velde, S., Nevens, F., Van Hee, P., Van Steenberghe, D., and Quirynen, M.: GC-MS analysis of breath odor compounds in liver patients, J. Chromat. B, 875, 344-348, 2008.

Van den Velde, S., van Steenberghe, D., Van Hee, P., and Quirynen, M.: Detection of odorous compounds in breath, J. Dent. Res., 88, 285-289, 2009.

Vandingenen, R., Jensen, N. R., Hjorth, J., and Raes, F.: Peroxynitrate formation during the nighttime oxidation of dimethylsulfide - Its role as a reservoir species for aerosol formation, J. Atmos. Chem., 18, 211-237, 1994.

Wang, T. S., Smith, D., and Spanel, P.: Selected ion flow tube, SIFT, studies of the reactions of $\mathrm{H}_{3} \mathrm{O}^{+}, \mathrm{NO}^{+}$and $\mathrm{O}_{2}^{+}$with compounds released by Pseudomonas and related bacteria, Int. J. Mass Spectrom., 233, 245-251, 2004.
Wardencki, W.: Problems with the determination of environmental sulphur compounds by gas chromatography, J. Chromatogr. A, 793, 1-19, 1998.

Watts, S. F.: The mass budgets of carbonyl sulfide, dimethyl sulfide, carbon disulfide and hydrogen sulfide, Atmos. Environ., 34, 761779, 2000.

Williams, J., Wang, N. Y., Cicerone, R. J., Yagi, K., Kurihara, M., and Terada, F.: Atmospheric methyl halides and dimethyl sulfide from cattle, Geophys. Res. Lett., 13, 485-491, 1999.

Williams, T. L., Adams, N. G., and Babcock, L. M.: Selected ion flow tube studies of $\mathrm{H}_{3} \mathrm{O}^{+}\left(\mathrm{H}_{2} \mathrm{O}\right)_{0,1}$ reactions with sulfides and thiols, Int. J. Mass Spectrom., 172, 149-159, 1998.

Xie, Z. Q., Sun, L. G., Wang, J. J., and Liu, B. Z.: A potential source of atmospheric sulfur from penguin colony emissions, J. Geophys. Res., 107, 4617, doi:10.1029/2002JD002114, 2002.

Yi, Z. G., Wang, X. M., Sheng, G. Y., and Fu, H. M.: Exchange of carbonyl sulfide (OCS) and dimethyl sulfide (DMS) between rice paddy fields and the atmosphere in subtropical China, Agr. Ecosyst. Environ., 123, 116-124, 2008.

Yin, F. D., Grosjean, D., and Seinfeld, J. H.: Photoxidation of dimethyl sulfide and dimethyl disulfide. I: Mechanism development, J. Atmos. Chem., 11, 309-364, 1990a.

Yin, F. D., Grosjean, D., Flagan, R. C., and Seinfeld, J. H.: Photooxidation of dimethyl sulfide and dimethyl disulfide. 2: Mechanism evaluation, J. Atmos. Chem., 11, 365-399, 1990b.

Zhang, H. Y., Schuchardt, F., Li, G. X., Yang, J. B., and Yang, Q. Y.: Emission of volatile sulfur compounds during composting of municipal solid waste (MSW), Waste Manage., 33, 957-963, 2013.

Zhang, R. Y., Khalizov, A., Wang, L., Hu, M., and Xu, W.: Nucleation and growth of nanoparticles in the atmosphere, Chem. Rev., 112, 1957-2011, 2012.

Zhao, J. and Zhang, R. Y.: Proton transfer reaction rate constants between hydronium ion $\left(\mathrm{H}_{3} \mathrm{O}^{+}\right)$and volatile organic compounds, Atmos. Environ., 38, 2177-2185, 2004.

Zhu, L., Nenes, A., Wine, P. H., and Nicovich, J. M.: Effects of aqueous organosulfur chemistry on particulate methanesulfonate to non-sea salt sulfate ratios in the marine atmosphere, J. Geophys. Res., 111, 1-15, 2006. 